most largely of $\mathrm{SrOH}^{-}$and $\mathrm{OH}^{+}$ions and un-ionized $\mathrm{Sr}(\mathrm{OH})_{2}$ with only an extremely small amount of the $\mathrm{Sr}^{++}$ion. Under this assumption the ions present, resulting from the dissociation of the two salts, would be almost altogether non-common ions, and the resulting curve should therefore have the same form as for the addition of a salt with no common ion.

Boston, Mass.

[Contributions from the Research Laboratory of Physical Chemistry of the MASSACHUSETTS INSTITUTE OF TEChNOLOGY. No. 78.]

\title{
THE EFFECTS OF SALTS UPON THE SOLUBILITY OF OTHER SALTS. VII. DISCUSSION OF THE SOLUBILITY RELATIONS OF UNIBIVALENT SALTS.
}

BY WiLltaM D. Harkins.

Received August 28, 1911.

\section{I8. Introduction.}

The data and discussion of the fifth and sixth papers of this series show that the solubility-product principle cannot be even approximately true for moderately soluble salts of the unibivalent type, when a common bivalent ion is added, if the concentration of the un-ionized part remains constant, or varies in the same direction as it always does with uni-univalent salts. In the case of this latter, more simple type of salt the concentration of the un-ionized part of the dissolved salt always decreases with the increase in total ion concentration. ${ }^{1}$ If this is true for unibivalent salts, the increase of solubility caused in some cases by the addition of a salt with a common bivalent ion must be accompanied by an enormous increase in the solubility-product. It is therefore of interest to consider these solubility data from a quantitative standpoint, in order to see how much of the variation of the solubility curves from what has been considered the theoretical form may be due to deviations from the solubility-product principle, and how much may be due to irregular behavior on the part of the un-ionized fraction.

With this end in view, calculations of the concentrations of the ionized and un-ionized parts of all of the salts have been made by the methods which have been employed in the study of uni-univalent salts. The method of calculation has been explained in the first paper of this series and illustrated in the fourth paper. ${ }^{2}$ It may be recalled that when no common ion is present the total ion concentration $(\Sigma i)$ is taken as the factor determining the ionization relations of the salts. A fundamental assumption made in this method of calculation is that intermediate ions of the type $\mathrm{AgSO}_{4}^{-}$or $\mathrm{BaBrO}_{3}^{+}$are not present. Indeed, it/ is

${ }^{1}$ See article IV of this series, This JOURnaL, 33, I683-5 (1911).

'See also Sherrill, This JoURNAL, 32, 74 (1910). 


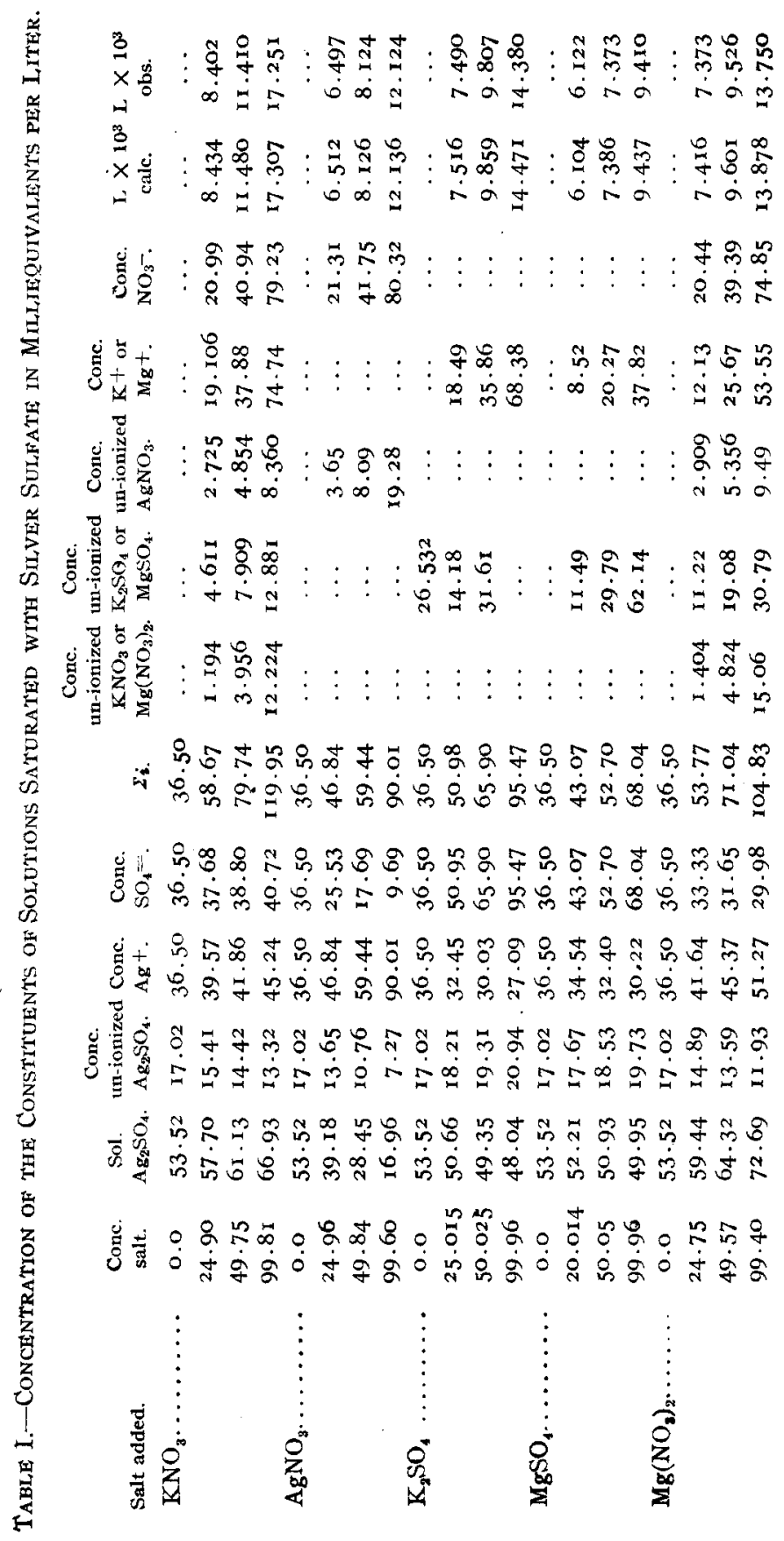


upon this assumption that our present values for the ionization of unibivalent salts are based.

\section{Calculation of the Concentration of the Constituents of Mixtures.}

The concentrations of the various constituents in the mixtures calculated in this way are given in Tables I to IV. The concentration of the un-ionized part of the saturating salt is given in the fourth column, the total ion concentrations in the sixth column, and the calculated and observed conductances in the last two columns. The conductance data upon which these calculations are based are given in Tables VIII to IX of the fifth paper of this series. The values of the equivalent conductances for all of the added salts were obtained by interpolation, while those for the dissolved salt were obtained by extrapolation, using the formula $\mathrm{I} / \Lambda=\mathrm{I} / \Lambda_{0}+K(C \Lambda)^{2-n}$, where the values of $K$ and $n$ were determined from the experimental values of $\Lambda$ for each salt, and $n$ was so chosen as to give nearly a straight line graph when the values of $I / \Lambda$ are plotted against $(C \Lambda)^{n}$. On account of the very low solubility of barium iodate it is not possible to determin the conductance accurately enough by Table III.-Concentration of the Constituents of Solutions Saturated with LEAD ChLORIDE IN MILLIEQUivalenTS PER LITER.

\begin{tabular}{|c|c|c|c|c|c|c|c|c|c|c|}
\hline $\begin{array}{c}\text { Salt } \\
\text { added. }\end{array}$ & $\begin{array}{l}\text { Conc. } \\
\text { salt. }\end{array}$ & $\begin{array}{c}\text { Sol. } \\
\mathrm{PbCl}_{2} \text {. }\end{array}$ & $\begin{array}{c}\text { Cone. } \\
\text { un-ion- } \\
\text { ized } \\
\mathrm{PbCl}_{2} .\end{array}$ & $\begin{array}{c}\text { Conc. } \\
\mathrm{Pb}++ \\
\text { ions. }\end{array}$ & $\begin{array}{l}\text { Conc. } \\
\mathrm{Cl}- \\
\text { ions. }\end{array}$ & si. & $\begin{array}{c}\text { Conc. } \\
\mathrm{KCl} \text { or } \\
\mathrm{Pb}\left(\mathrm{NO}_{3}\right)_{2}\end{array}$ & $\begin{array}{l}\text { Conc. } \\
\mathrm{K}+\text { or } \\
\mathrm{NO}_{3}-\end{array}$ & $\begin{array}{c}L \times 10^{3} \\
\text { calc. }\end{array}$ & $\begin{array}{c}I \times 10^{3} \\
\text { meas. }\end{array}$ \\
\hline \multirow[t]{3}{*}{$\mathrm{KCl} \ldots}$. & 0.0 & $77 \cdot 76$ & 34 . II & 43.65 & 43.65 & 43.65 & 0.0 & 0.0 & $\ldots$ & . \\
\hline & 50.0 & 48 & 24.76 & $23 \cdot 44$ & 87 & 66.87 & 6.57 & 43.43 & & $\cdots$ \\
\hline & 100.0 & 34.10 & 19.88 & I 4.22 & 99.18 & 99.18 & $3 \times 5.04$ & 96 & $\ldots$ & $\cdots$ \\
\hline \multirow[t]{4}{*}{$\mathrm{Pb}\left(\mathrm{NO}_{2}\right)_{2}$} & 20.0 & $77 \cdot 76$ & $34 . I I$ & 43.65 & 43.65 & 43.65 & 0.0 & 0.0 & 6.42 & . \\
\hline & I9.980 & 76.75 & 36.41 & $53 \cdot 5^{6}$ & $40 \cdot 34$ & $53 \cdot 56$ & 6.76 & 13.22 & 7.803 & . \\
\hline & 50.003 & 76.64 & 39.67 & 68.44 & 36.97 & 68.44 & 18.53 & 31.47 & 9.894 & . \\
\hline & 99.49 & 77.98 & $44 \cdot 43$ & 91.85 & 33.55 & 91.85 & 341.19 & $5^{8} \cdot 3$ & 13.199 & 13.12 \\
\hline
\end{tabular}

Table IV.-Concentration of the Constituents of Solutions Saturated with BARIUM IODATE IN MILIIEQUIVALENTS PER LITER.

\begin{tabular}{|c|c|c|c|c|c|c|c|c|}
\hline Salt added. & $\begin{array}{l}\text { Conc. } \\
\text { salt. }\end{array}$ & $\begin{array}{c}\text { Sol. } \\
\mathrm{Ba}\left(\mathrm{IO}_{3}\right)_{2} .\end{array}$ & $\begin{array}{c}\text { Conc. } \\
\text { un-ionized } \\
\mathrm{Ba}\left(\mathrm{IO}_{3}\right)_{2} .\end{array}$ & $\begin{array}{l}\text { Cone. } \\
\text { Bat } \\
\text { ions. }\end{array}$ & $\begin{array}{l}\text { Conc. } \\
\mathrm{IO}_{3}- \\
\text { ions. }\end{array}$ & $\Sigma i$. & $\begin{array}{c}\text { Conc. } \\
\mathrm{Ba}\left(\mathrm{NO}_{3}\right)_{2},\end{array}$ & $\begin{array}{c}\text { Conc. } \\
\mathrm{NO}_{3}-\text { or } \\
\mathrm{K}-\text { ions. }\end{array}$ \\
\hline \multirow[t]{8}{*}{$\mathrm{Ba}\left(\mathrm{NO}_{2}\right)_{2}$} & 0.0 & I. 579 & $0.09 \mathrm{r}$ & I. 488 & I. 488 & I. 488 & 0.0 & $\ldots$ \\
\hline & 1.0 & 1.362 & 0.092 & 2.199 & 1.270 & 2.199 & $0.07 I$ & 0.929 \\
\hline & 2.0 & I.2I2 & 0.094 & 2.951 & I.II 8 & 2.951 & 0.166 & I. 834 \\
\hline & 5.0 & 0.9753 & 0.101 & $5 \cdot 3$ I 8 & 0.873 & $5 \cdot 318$ & $0.55^{\circ}$ & $4.45^{\circ}$ \\
\hline & 20.0 & 0.6744 & O.II 8 & 16.85 & $0.55^{6}$ & I 6.85 & $4 \cdot 70$ & I 6.30 \\
\hline & 50.0 & $0.6 \mathrm{I} 3 \mathrm{I}$ & 0.140 & $37 \cdot 57$ & 0.472 & $37 \cdot 57$ & 12.90 & $37 \cdot 10$ \\
\hline & 100.0 & $0.5^{659}$ & 0.172 & 67.99 & 0.393 & 67.99 & 32.40 & 67.60 \\
\hline & 200.0 & 0.5580 & 0.206 & 120.80 & $0.35 \mathrm{I}$ & 120.80 & 79.6 & 120.4 \\
\hline \multirow[t]{3}{*}{$\mathrm{KIO}_{2} .}$. & 0.0 & I. 579 & $0.09 \mathrm{I}$ & I . 488 & 1.488 & 1.488 & $\ldots$ & $\cdots$ \\
\hline & 0.5304 & $4 \mathrm{I} .242$ & 0.072 & I. 170 & I. 683 & I. 683 & 0.0174 & 0.513 \\
\hline & 1.0608 & 80.9418 & 0.059 & 0.883 & I. .908 & 1.908 & 0.037 & 1.024 \\
\hline
\end{tabular}


extrapolation, so the assumption was made that the ionization of barium iodate differs from that of barium nitrate by the same percentage that the ionization of potassium iodate differs from that of potassium nitrate. The values used were those obtained at ${ }_{1} 8^{\circ}$ by Kohlrausch. The values for the ionization of silver lead sulfate were obtained by dividing the equivalent conductance, as obtained by extrapolation, by the equivalent conductance at zero concentration as given by Hunt. ${ }^{1}$ When the ionization values thus obtained were plotted against the total ion concentration the curve was almost the same as that obtained experimentally for thallous sulfate, though for the higher ion concentrations the ionization of silver sulfate is slightly larger. The ionization of barium bromate at the higher ion concentrations was calculated entirely from the extrapolated values of the equivalent conductance. A comparison of the ionization curve with that for barium nitrate makes it seem probable that the values of the ionization obtained for barium bromate are slightly too high for the higher concentrations. However, as it is not certain that these values are too high, and since any correction which should be made is so small that it would. make no appreciable difference in the calculations, the values obtained by extrapolation have not been changed.

\section{The Solubility Product.}

The chief interest in the results presented in Tables I to IV centers in the change of the solubility product $\left(\mathrm{B}^{+}\right)^{2}\left(\mathrm{~A}^{=}\right)$or $\left(\mathrm{B}^{++}\right)\left(\mathrm{A}^{-}\right)^{2}$ and of the concentration of the un-ionized part $\mathrm{B}_{2} \mathrm{~A}$ or $\mathrm{BA}_{2}$ with the total ion concentration (or with the total salt concentration). In this connection

Table V.-Values of the Solubility Product for Silver Sulfate in the PresENCE OF OTHER SALTS.

\begin{tabular}{|c|c|c|c|c|c|}
\hline \multicolumn{6}{|c|}{ ( $\Sigma i$ in milliequivalents, solubility product in millimoles.) } \\
\hline$\Sigma i$. & $\mathrm{KNO}_{3}$ & $\mathrm{AgNO}_{3}$ & $\mathrm{~K}_{\mathrm{2}} \mathrm{SO}_{4}$ & $\mathrm{MgSO}_{4}$. & $\mathrm{Mg}\left(\mathrm{NO}_{3}\right)_{2}$ \\
\hline 36.50 & 24320 & 24320 & 24320 & 24320 & 24320 \\
\hline 43.07 & $\ldots$ & $\cdots$ & ... & 25700 & $\cdots$ \\
\hline 46.84 & ... & 28010 & . & $\ldots$ & $\cdots$ \\
\hline 50.98 & $\cdots$ & $\cdots$ & 26790 & $\cdots$ & $\cdots$ \\
\hline $52 \cdot 70$ & ... & $\ldots$ & $\cdots$ & 27700 & $\ldots$ \\
\hline 53.77 & $\ldots$ & $\ldots$ & $\ldots$ & $\ldots$ & 28900 \\
\hline 58.67 & 29480 & $\ldots$ & $\ldots$ & $\ldots$ & $\ldots$ \\
\hline 59.44 & $\ldots$ & $3 \times 280$ & $\ldots$ & $\ldots$ & $\ldots$ \\
\hline 65.90 & $\ldots$ & $\ldots$ & $2973^{\circ}$ & $\ldots$ & $\ldots$ \\
\hline 68.04 & $\ldots$ & $\ldots$ & $\ldots$ & 31100 & $\ldots$ \\
\hline 71.04 & $\ldots$ & $\cdots$ & $\ldots$ & $\ldots$ & 32570 \\
\hline $79 \cdot 74$ & 33930 & $\cdots$ & $\cdots$ & $\cdots$ & $\cdots$ \\
\hline 90.01 & $\ldots$ & 39250 & $\ldots$ & $\ldots$ & $\ldots$ \\
\hline $95 \cdot 47$ & $\ldots$ & $\ldots$ & 35080 & $\cdots$ & $\cdots$ \\
\hline 104.83 & $\ldots$ & $\ldots$ & $\cdots$ & $\ldots$ & 39410 \\
\hline II 9.95 & 41600 & $\ldots$ & $\ldots$ & $\cdots$ & $\cdots$ \\
\hline
\end{tabular}


EFFECT OF SALTS UPON THE SOLUBILITY OF OTHER SALTS. VII. I84I

the change of concentration of the un-ionized part is the more interesting on account of the very great irregularity of its behavior, but the discussion of this subject will be deferred until the values for the solubility product have been presented. These values, with the corresponding total ion concentrations, are given in Tables $\mathrm{V}$ to VIII.

Table VI.-Values of the Solubility Product for Baritum Bromate in the PRESENCE OF OTHER SALTS.

( $\Sigma i$ in milliequivalents, solubility product in millimoles.)

$\begin{array}{cccc}\Sigma i . & \mathrm{KNO}_{3} . & \mathrm{KBrO}_{3} & \mathrm{Ba}\left(\mathrm{NO}_{3}\right)_{2} . \\ 30.50 & 14190 & 14190 & 14190 \\ 41.17 & \ldots & 16880 & \ldots \\ 44.42 & \ldots & \ldots & 15430 \\ 52.4 \mathrm{I} & 17330 & \ldots & \ldots \\ 54.94 & \ldots & 18420 & \ldots \\ 58.79 & \ldots & \ldots & 17210 \\ 73.34 & 20080 & \ldots & \ldots \\ 86.05 & \ldots & \ldots & 19800 \\ 88.04 & \ldots & 22230 & \ldots \\ \mathrm{I} 12.59 & 24370 & \ldots & \ldots\end{array}$

Table Vil.-Values of the Solubility Product for Lead Chloride in The PreAsence OF OTHER SALTS.

( $\Sigma i$ in milliequivalents, solubility product in millimoles.)

$\Sigma i$.

43.65

$53 \cdot 56$

66.87

68.44

91.85

99.18
KCl.

4. 162
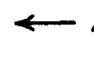

50000

...

69880
$\mathrm{Pb}\left(\mathrm{NO}_{3}\right)_{2}$

41620

43580

...

$4673^{\circ}$

51700

$\therefore$

Table VIII.-Values of the Solubility Product for Barium Iodate in the PRESENCE OF BARIUM NITRATE.

( $\Sigma i$ in milliequivalents, solubility product in millimoles.)

si.

$\mathrm{I} .488$

2. 199

2.951

$5 \cdot 318$

I 6.85

$37 \cdot 57$

67.99

120.80
I. 648

I. 773

I. 846

2.025

2.606

4. 185

5.245

7.880

The most striking result presented in these tables is that there is no approach to constancy in the values of the solubility product; for example, it increases $7 \mathrm{I}$ per cent. when 0.1 normal potassium nitrate is added to silver sulfate. Under the same conditions the solubility product for 
barium bromate increases about 72 per cent., while that for thallous chloride, a uni-univalent salt, increases only $181 / 2$ per cent., although the corresponding increase in the total ion concentration is much greater than for either of the unibivalent salts.

Fig. I shows the solubility products for lead chloride, silver sulfate, barium bromate, and for thallous chloride plotted as ordinates against

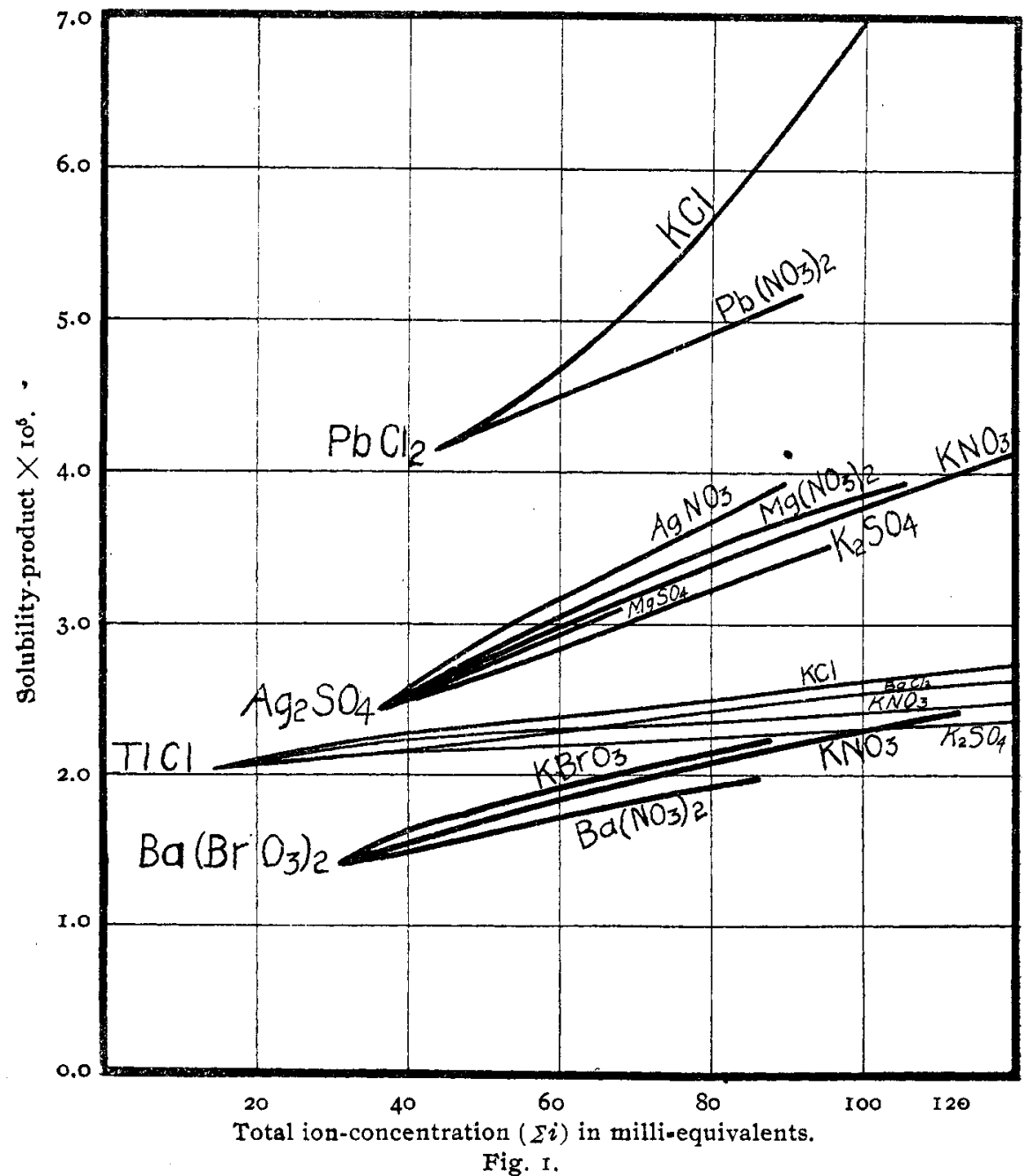

the corresponding total ion concentrations as abscissas. It will be seen that the solubility product for the uni-univalent salt thallous chloride increases somewhat, but not very greatly, with an increase in the total 
ion concentration, ${ }^{1}$ but that in the case of the unibivalent salts with about the same degree of solubility, the solubility product increases very rapidly with the increase in total ion concentration $\left(\Sigma_{i}\right)$ and the increase is much greater for some types of added salts than for others. The increase is greatest when the added salt contains a common univalent ion, and least when it contains a common bivalent ion. Moreover, in the one case in which the comparison is possible, that of silver sulfate, this increase is less rapid when the added salt with the common bivalent ion is a unibivalent salt than when it is a bi-bivalent salt. In the same way, the increase in the solubility product when the added salt contains no common ion is slightly greater when the added salt is unibivalent than when it is uni-univalent. The increase in the solubility product for lead chloride is extremely great when the salt with a common univalent ion is increased in concentration from 0.05 to o. I normal. It is of interest to note that lead chloride is the salt which shows the most abnormal increase in total solubility when a salt with a common bivalent ion is added.

In Fig. 2 the logarithms of the solubility product for the various

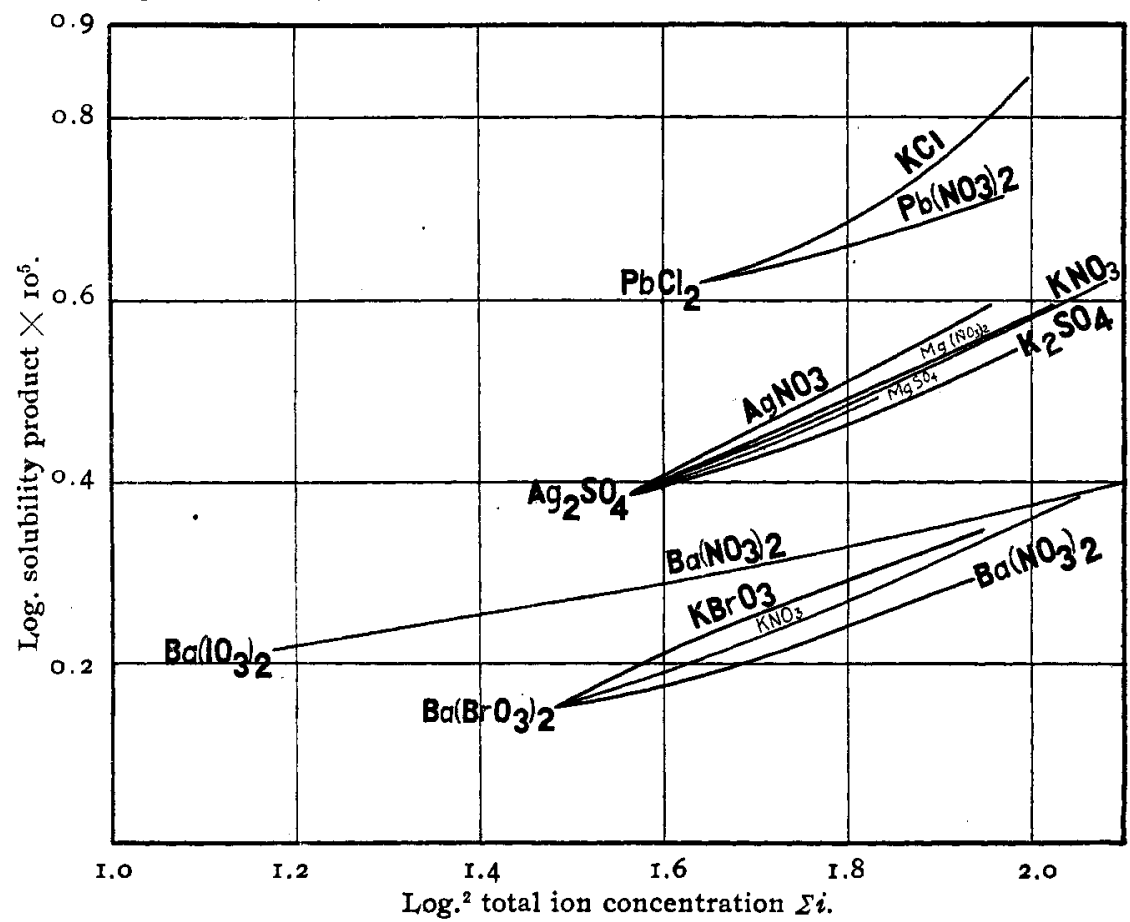

Fig. 2.

1 This result is typical foriuni-univalent saltsas shown in the fourth paper of this series.

- To get the characteristics for barium iodate subtract 4 on the $y$ axis and 1 on the $x$ axis. 
salts are plotted as ordinates and the logarithms of the corresponding total ion concentration as abscissas. This figure shows more clearly than Fig. I the rate of change of the solubility product. Barium iodate is the only salt investigated having a very small solubility ( 1.578 milliequivalents per liter); and with this salt the rate of increase of the solubility product with the total concentration is very much less than with the more soluble salts, barium bromate (40. I 8 milliequivalents per liter), silver sulfate $\left(53.5^{2}\right.$ milliequivalents per liter), and lead chloride $(77.76$ milliequivalents per liter). This is very marked up to a total ion concentration of 5.3 milliequivalents per liter for solutions of barium iodate. In the more concentrated solutions, with a concentration of added salt between $5^{\circ}$ and 100 millinormal ( $\Sigma i$ between 37 and 68 ), the solubility product increases at about the same rate as it does with the more soluble salts at the same ion concentrations. This fact, taken together with the data presented in the sixth paper of this series, shows that the solubility product becomes more constant as the solution becomes more dilute, and that the solubility-product principle is very nearly true for such difficultly soluble salts as lead iodate, even when the common bivalent ion is added, provided that the total ion concentration is kept very small. The statement is therefore undoubtedly correct that the solubility-product principle is true whenever the solution is extremely dilute. There seems to be some influence, which is particularly strong in the case of salts of the unibivalent type, which causes a greater and greater deviation from this principle as the concentration of the solution increases.

The relationship between the solubility product (SP) and the total ion concentration $(\Sigma i)$ may be expressed by an equation of the form

$$
(\mathrm{SP})=k_{i}(\Sigma i)^{m_{i}}
$$

This form has been chosen since it is similar to that used to represent the relationship between the ionized and un-ionized parts and the total ion concentration. ${ }^{1}$. The values of $m_{i}$ may be most easily determined from the curves in Fig. 2 by getting the slope of the tangent at any point. The equation is therefore most easily used in the form

$$
\log (\mathrm{SP})=\log k_{i}+m_{i} \log (\Sigma i) .
$$

An examination of the values of $m_{i}$, disregarding those for thallous sulfate because of its high solubility and those for lead chloride at the higher concentrations because its behavior is evidently exceptional, indicates that the value of $m_{i}$ for the ion concentration interval 30-IO0 millinormal does not differ greatly from 0.45 whatever be the nature of the ions present in the solution, provided the concentration of the common bivalent ion be not increased. When the latter ion is increased in concentration, a somewhat lower value of $m_{i}$ results, namely about 0.34 .

$$
1\left(\mathrm{~A}^{+}\right)\left(\mathrm{B}^{-}\right) /(\mathrm{AB})=K(\Sigma i)^{2-n} \text {. }
$$


EFFECT OF SALTS UPON THE SOLUBILITY OF OTHER SALTS. VII, 1845

TABLE IX.-VALUES OF $m_{i}$ AND LOG $k_{i 0}$ IN THE EQUATION LOG $10\left[\left(\mathrm{~B}^{+}\right)^{2}\left(\mathrm{~A}^{=}\right)\right.$OR $\left.\left(\mathrm{B}^{++}\right)\left(\mathrm{A}^{-}\right)^{2}\right]=\operatorname{LOG}_{10} k_{i}+m_{i} \operatorname{LOG}_{10}(\Sigma i)$.

\begin{tabular}{|c|c|c|c|c|c|}
\hline \multirow{2}{*}{$\begin{array}{l}\text { Salt } B_{2} A \\
\text { or } \mathrm{BA}_{2} \text {. }\end{array}$} & \multirow{2}{*}{ Added salt. } & $m i$. & $\log k_{i}$ & \multicolumn{2}{|c|}{ Limits of $\Sigma i$. } \\
\hline & & nmon & alent Ion & ed. & \\
\hline $\begin{array}{l}\mathrm{Tl}_{2} \mathrm{SO}_{4}{ }^{4} \\
\mathrm{PbCl}_{2}\end{array}$ & $\begin{array}{l}\mathrm{THNO}_{3} \\
\mathrm{KCl}\end{array}$ & $\begin{array}{l}0.88 \\
0.44 \\
0.85\end{array}$ & $\begin{array}{r}\ldots \\
+4.340 \\
+4.000\end{array}$ & $\begin{array}{r}234.0 \\
43.85 \\
66.87\end{array}$ & $\begin{array}{c}312.8 \\
66.87 \\
99.18\end{array}$ \\
\hline $\begin{array}{l}\mathrm{Ag}_{2} \mathrm{SO}_{4} \\
\mathrm{Ba}\left(\mathrm{BrO}_{3}\right)_{2}\end{array}$ & $\begin{array}{l}\mathrm{AgNO}_{3} \\
\mathrm{KBrO}_{3}\end{array}$ & $\begin{array}{l}0.53 \\
0.43\end{array}$ & $\begin{array}{l}+4.085 \\
+4.055\end{array}$ & $\begin{array}{l}36.50 \\
30.50\end{array}$ & $\begin{array}{l}90.01 \\
88.04\end{array}$ \\
\hline \multicolumn{6}{|c|}{ Salt with No Common Ion Added. } \\
\hline $\mathrm{Ag}_{2} \mathrm{SO}_{4}$ & $\begin{array}{l}\mathrm{KNO}_{3} \\
\mathrm{Mg}\left(\mathrm{NO}_{3}\right)_{2}\end{array}$ & $\begin{array}{l}0.45 \\
0.45\end{array}$ & $\begin{array}{l}+4 \cdot 134 \\
+4 \cdot 154\end{array}$ & $\begin{array}{l}36.50 \\
36.50\end{array}$ & $\begin{array}{l}\text { I } 19.95 \\
\text { I04.83 }\end{array}$ \\
\hline \multicolumn{6}{|c|}{ Salt with Common Bivalent Ion Added. } \\
\hline $\begin{array}{l}\mathrm{Tl}_{2} \mathrm{SO}_{4}{ }^{1} \\
\mathrm{PbCl}_{2} \\
\mathrm{Ag}_{2} \mathrm{SO}_{4}\end{array}$ & $\begin{array}{l}\mathrm{Na}_{2} \mathrm{SO}_{4} \\
\mathrm{~Pb}\left(\mathrm{NO}_{3}\right)_{2} \\
\mathrm{~K}_{2} \mathrm{SO}_{4} \\
\mathrm{MgSO}_{4}\end{array}$ & $\begin{array}{l}0.27 \\
0.29 \\
0.38 \\
0.39\end{array}$ & $\begin{array}{l}+4.043 \\
+4.43 \\
+4.170 \\
+4.165\end{array}$ & $\begin{array}{r}234.0 \\
43.65 \\
36.50 \\
36.50\end{array}$ & $\begin{array}{r}334.4 \\
9 \mathrm{I} .85 \\
95.47 \\
68.04\end{array}$ \\
\hline $\mathrm{Ba}\left(\mathrm{BrO}_{3}\right)_{2}$ & $\mathrm{Ba}\left(\mathrm{NO}_{3}\right)_{2}$ & 0.30 & +4.007 & 30.50 & 86.05 \\
\hline $\mathrm{Ba}\left(\mathrm{IO}_{3}\right)_{2}$ & $\mathrm{Ba}\left(\mathrm{NO}_{3}\right)_{2}$ & 0.17 & 0.187 & I. 49 & $5 \cdot 3$ \\
\hline
\end{tabular}

\section{The Concentration of the Un-ionized Part.}

When salts are added to saturated solutions of non-electrolytes the solubility of the non-electrolyte is, in general, decreased. This is what is known as the "salting out effect.". The general magnitude of this effect may be judged from the results upon the solubility of phenylthiocarbamide as determined by Rothmund $^{2}$ and by Biltz. ${ }^{3}$ They are expressed by Rothmund as the percentage lowering in solubility caused by the addition of one equivalent of the salt to one liter of the solution. In Table $\mathrm{X}$ these values divided by Io are given. They represent approximately the percentage lowering caused by a tenth-normal salt solution. TABle X.-Percentage Lowering OF THE Sol,ubility OF PHENYLthiocarbamide at $20^{\circ}$, CaUsed by the Presence of o. I Normal Salt.

\begin{tabular}{|c|c|c|c|}
\hline $\mathrm{NH}_{4} \mathrm{NO}_{3} \ldots \ldots \ldots \ldots$ & -0.7 & $\ldots \ldots \ldots$ & 2.4 \\
\hline $\mathbf{K I} \ldots \ldots \ldots \ldots \ldots$ & -0.4 & $\mathrm{CuCl}_{2}$. & 2.5 \\
\hline NaI... & 0.07 & $\mathrm{NaCl}$ & 2.8 \\
\hline $\mathrm{KNO}_{3} \ldots \ldots \ldots \ldots \ldots$ & 0.8 & $\left(\mathrm{NH}_{4}\right)_{2} \mathrm{SO}_{4} \ldots \ldots \ldots \ldots \ldots$ & 2.8 \\
\hline $\mathrm{NaNO}_{3} \ldots \ldots \ldots \ldots \ldots$ & I.O & $\mathrm{MgSO}_{4} \ldots \ldots \ldots \ldots \ldots \ldots$ & 3.2 \\
\hline $\mathrm{KClO}_{3} \ldots \ldots \ldots \ldots \ldots$ & 1.22 &,$\ldots \ldots \ldots \ldots \ldots \ldots$ & $3 \cdot 7$ \\
\hline $\mathrm{NaClO}_{3} \ldots \ldots \ldots \ldots$ & I. 26 & $\mathrm{Na}_{2} \mathrm{CO}_{3} \ldots \ldots \ldots \ldots \ldots \ldots$ & 3.8 \\
\hline $\mathrm{KC}_{2} \mathrm{H}_{3} \mathrm{O}_{2} \ldots \ldots \ldots \ldots$ & $2 \cdot 3$ & $\mathrm{Na}_{3} \mathrm{SO}_{4} \ldots \ldots \ldots \ldots \ldots \ldots$ & $4 \cdot I$ \\
\hline
\end{tabular}

1 These results for thallous sulfate are derived from the data given in Table $X$ of Paper IV of this series.

'Rothmund, Z. physik. Chem., 33, 401 (1900).

${ }^{3}$ Biltz, Ibid., 43, 4I (1903). 
The maximum lowering given by Rothmund ${ }^{1}$ is about 5.4 per cent., viz., that produced when 0 . I equivalent sodium carbonate or sodium sulfate is added to aqueous solutions of ethyl ether at $18 .^{2}$ The percentage lowerings in the solubility of nitrous oxide, oxygen, and carbon dioxide, caused by 0 . I normal sulfuric acid, are $0.87,1.07$ and 0.68 , respectively. If the salts are arranged in the order in which they affect the solubility of one non-electrolyte, they are, with few exceptions, arranged in the order in which they influence the solubility of any other slightly soluble non-electrolyte. The constancy of the magnitude of the equivalent lowering of solubility may be judged from the following values obtained by adding magnesium sulfate to solutions of the following substances: Hydrogen, 23 ; nitrous oxide, 29 ; carbon dioxide, 30 ; phenylthiocarbamide, 32 ; ethyl acetate, 39; and from the following ones obtained when sodium chloride is the added salt: Hydrogen, 2I.5; nitrogen, 34; nitrous oxide, 24; oxygen, 27.6; carbon dioxide, 21 ; hydrogen sulfide, 15 ; phenylthiocarbamide, 28; ethyl acetate, 34; and ethyl- ether, 42. (All of the results for ethyl ether are very high.)

If then, the un-ionized part of a salt in aqueous solution is similar in its properties to a non-electrolyte, it would be expected that the addition of 0 . I normal potassium chloride would cause a decrease in solubility of about 2.4 per cent.; of 0 . I normal potassium sulfate, a decrease of about 3.7 per cent.; and of potassium nitrate, of about 0.8 per cent. The results for the uni-univalent type of $\mathrm{salt}^{3}$, have shown that the solubility of the un-ionized part of thallous chloride decreases from 17.55 milliequivalents in pure water to 9.7 in tenth-normal potassium nitrate solution, to 9.7 in tenth-normal potassium sulfate solution, and to 10.9 in tenthnormal thallous sulfate solution, that is, by $44.7,44.7$, and 37.9 per cent., respectively. This is more than io times the lowering caused by the salting out of non-electrolytes. It seems clear then that the lowering of the solubility of the un-ionized part of an electrolyte caused by the addition of a salt is of a different order of magnitude from the ordinary salting-out effect. ${ }^{4}$

When salts of different types are added in solutions of uni-univalent salts, the concentration of the un-ionized part of the latter has been shown ${ }^{5}$ to be decreased by practically the same amount by the same change in

1 "Loslichkeit und Löslichkeits Beeinflussigung," p. I53.

Euler, Z. physik. Chem., 49, 303 (1904).

${ }^{3}$ See the fourth paper of this series.

4 This may be considered as an argument in favor of the consideration of the unionized part of a salt as a complex, rather than as an individual substance. It is probable that the equilibria involved in the process of solution are more numerous than is usually supposed. Thus it seems probable that the solid phase is itself partly ionized.

'Bray, Paper IV of this series, This Journal, 33, I676 (I911). 
EFFECT OF SALTS UPON THE SOLUBILITY OF OTHER SALTS. VII. I847

total ion concentration $(\Sigma i)$ whether the added salt is uni-univalent or unibivalent, and whether it has a common ion or no common ion. Thus the values of the concentration of the un-ionized part of thallous chloride in different solutions saturated with it, at the corresponding total ion concentrations $(\Sigma i)$ are as follows:

\begin{tabular}{|c|c|c|}
\hline Added salt. & $\Sigma i$. & Conc. un-ionized TlCl. \\
\hline None....... & 14 & I. 755 \\
\hline O.I $N \mathrm{KNO}_{3}$ & 97 & 0.97 \\
\hline $0 . \mathrm{I} N \mathrm{~K}_{2} \mathrm{SO}_{4}$ & 85 & 0.97 \\
\hline o. I $N \mathrm{Tl}_{2} \mathrm{SO}_{4}$ & 64 & 1.09 \\
\hline
\end{tabular}

The results for unibivalent salts are very different, as will be seen from Tables XI to XIV.

Table XI.-Concentration of the Un-IOnized Part of Silver Sulfate in Solutions OF OTher Salts. (CONCENTRATIONS IN MiLLIEQUIVALENTS PER Liter.)

$\begin{array}{rccccc}\Sigma_{i .} & \mathrm{KNO}_{3} . & \mathrm{Mg}\left(\mathrm{NO}_{3}\right)_{2} . & \mathrm{AgNO}_{3} . & \mathrm{K}_{2} \mathrm{SO}_{4} . & \mathrm{MgSO}_{4} \\ 36.50 & 17.02 & 17.02 & 17.02 & 17.02 & 17.02 \\ 43.07 & \ldots & \ldots & \ldots & \ldots & 17.67 \\ 46.84 & \ldots & \ldots & 13.65 & \ldots & \ldots \\ 50.98 & \ldots & \ldots & \ldots & 18.2 \mathrm{I} & \ldots \\ 52.70 & \ldots & \ldots & \ldots & \ldots & 18.57 \\ 53.77 & \ldots & 14.89 & \ldots & \ldots & \ldots \\ 58.67 & 15.4 \mathrm{I} & \ldots & \ldots & \ldots & \ldots \\ 59.44 & \ldots & \ldots & 10.76 & \ldots & \ldots \\ 65.90 & \ldots & \ldots & \ldots & 19.3 \mathrm{I} & \ldots \\ 68.04 & \ldots & \ldots & \ldots & \ldots & 19.73 \\ 71.04 & \ldots & 13.59 & \ldots & \ldots & \ldots \\ 79.74 & 1442 & \ldots & \ldots & \ldots & \ldots \\ 90.01 & \ldots & \ldots & 7.27 & \ldots & \ldots \\ 95.47 & \ldots & \ldots & \ldots & 20.94 & \ldots \\ 104.83 & \ldots & 11.93 & \ldots & \ldots & \ldots \\ 119.95 & 13.32 & \ldots & \ldots & \ldots & \ldots\end{array}$

Table XII.-Concentration of the Un-tonized Part of Bartum Bromate in SOLUTIONS OF OTHER SALTS.

$\begin{array}{cccc}\Sigma i . & \mathrm{KNO}_{3 .} & \mathrm{KBrO}_{3 .} & \mathrm{Ba}\left(\mathrm{NO}_{3}\right)_{2 .} \\ 30.50 & 9.68 & 9.68 & 9.68 \\ 41.17 & \ldots \ldots & 7.15 & \ldots \\ 44.42 & \ldots \ldots & \ldots \ldots & 10.09 \\ 52.41 & 8.17 & \ldots \ldots & \ldots \\ 54.94 & \ldots \ldots & 5.17 & \ldots \\ 58.79 & \ldots \ldots & \ldots . & 10.55 \\ 73.34 & 7.38 & \ldots . & \ldots \\ 86.05 & \ldots \ldots & \ldots . & 11.15 \\ 88.04 & \ldots \ldots & 3.02 & \ldots \\ 112.59 & 6.57 & \ldots \ldots & \ldots\end{array}$


Table XIII.-Concentration of the Un-ionized Part of Lead Chloride in Sol, TIONS OF OTHER SALTS.

$\begin{array}{ccc}\Sigma i . & \mathrm{KCl} & \mathrm{Pb}\left(\mathrm{NO}_{3}\right)_{2} . \\ 43.65 & 34 . \mathrm{II} & 34 . \mathrm{II} \\ 53.56 & \ldots & 36.4 \mathrm{I} \\ 66.87 & 24.76 & \ldots \\ 68.44 & \ldots & 39.67 \\ 91.85 & \ldots & 44.43 \\ 99.18 & 19.88 & \ldots\end{array}$

Table XIV.-Concentration of the Un-IOnized Part of Barium Iodate in SOLUTIONS OF OTHER SALTS.

\begin{tabular}{rcc}
\multicolumn{1}{c}{ i. } & $\mathrm{Ba}\left(\mathrm{NO}_{3}\right)_{2}$ & $\mathrm{KIO}{ }_{3}$ \\
$I .488$ & $0.09 \mathrm{I}$ & $0.09 \mathrm{I}$ \\
$\mathrm{I} .683$ & $\ldots$ & 0.072 \\
$\mathrm{I} .908$ & $\ldots$ & 0.059 \\
2.199 & 0.092 & $\ldots$ \\
$2.95 \mathrm{I}$ & 0.094 & $\ldots$ \\
5.318 & 0.101 & $\ldots$ \\
16.85 & 0.118 & $\ldots$ \\
37.57 & 0.140 & $\ldots$ \\
67.99 & 0.172 & $\ldots$ \\
120.80 & 0.206 & $\ldots$
\end{tabular}

The results presented in Tables XI to XIV are expressed graphically in Fig. 3, where the ordinates represent the logarithm of the "un-ionized concentration" of the "saturating salt," and the abscissas the logarithm of the total ion concentration. These tables and figures show that the un-ionized part is very much more irregular in its behavior than the solubility product (see Figs. I and 2), and also very much more irregular than the un-ionized part of a uni-univalent salt. The latter fact is made plain by Fig. 3, where the lines representing the change in concentration of un-ionized thallous chloride lie so close together that they make almost one line, while the curves for the unibivalent salts diverge widely in the shape of a fan.

Certain remarkable regularities are observed when the "saturating salt" is of the unibivalent type:

(I) When a salt with a common bivalent ion is added the concentration of the un-ionized part of the "saturating salt" always increases rapidly, and this is true whether the added salt is unibivalent or bi-bivalent. This is quite contrary to what is known in regard to the solubility of the unionized part of uni-univalent salts in dilute solutions. This increase corresponds to the increase in the total solubility of the salt (see Fig. I, fifth paper of this series, and discussion) when a salt with a common bivalent ion is added.

(2) When a salt with no common ion is added, the solubility of the un- 
EFFECT OF SALTS UPON THE SOLUBILITY OF OTHER SALTS. VII. I849

ionized part decreases with increasing total ion concentration, and at about the same rate as the un-ionized part of the uni-univalent salt, thallous chloride decreases. The un-ionized part of a uni-univalent salt decreases at a certain rate with the increase in the total ion concentration, and this

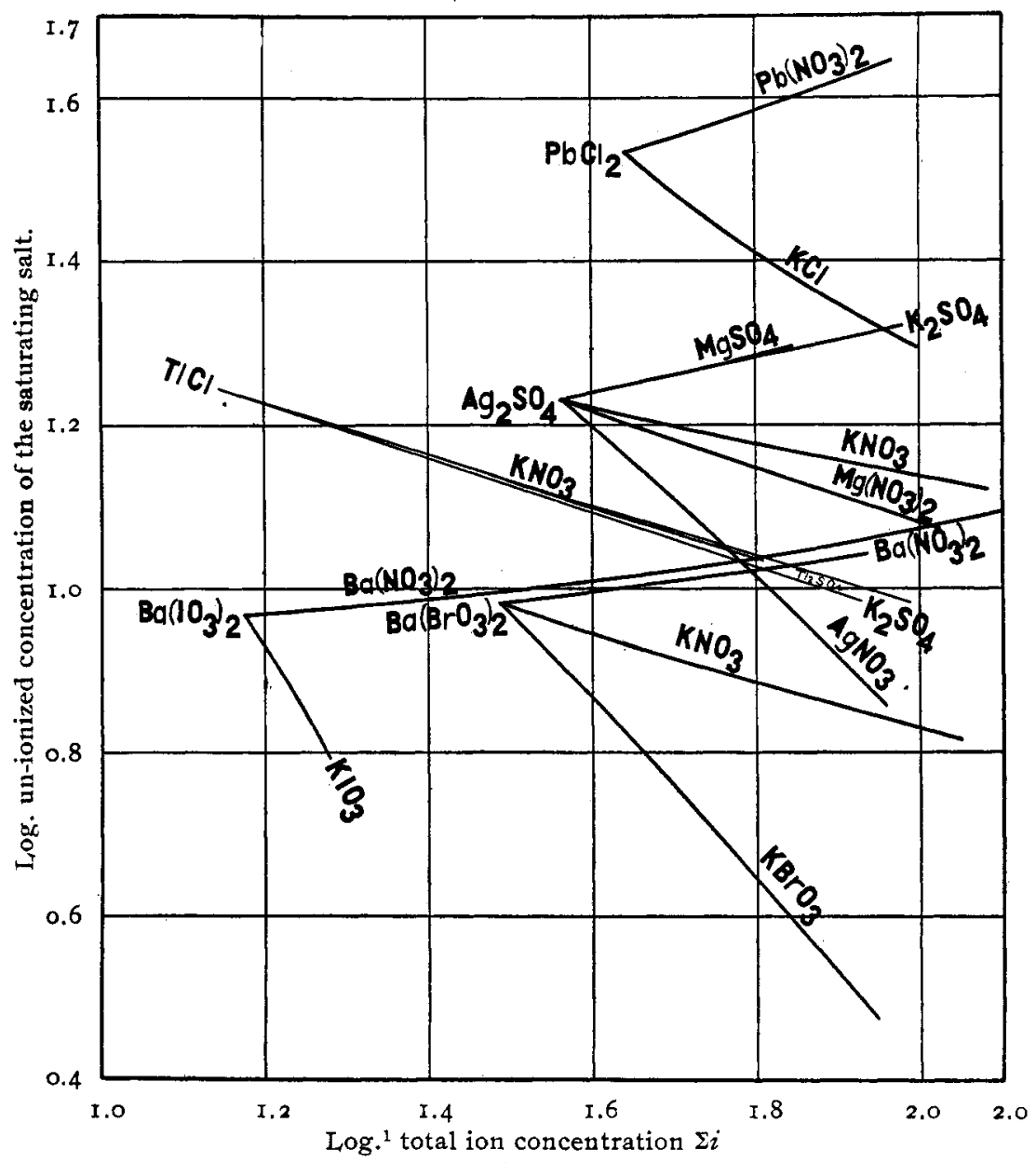

Fig. 3.

rate of decrease is practically the same whether the added salt contains a common ion or not, and whether it is uni-univalent or unibivalent; furthermore, this rate of decrease for the one case investigated is also practically the same as that of the un-ionized unibivalent salt, but only when the salt added to the latter contains no common ion.

(3) When a salt with a common univalent ion is added, the un-ionized

${ }^{1}$ To get the characteristics for barium iodate 2 on the $y$ axis, and $\mathrm{I}$ on the $x$ axis. 
concentration of the saturating univalent salt decreases with extreme rapidity, and at a rate which is not at all comparable with that for uniunivalent salts.

The results represented by Fig. 3 may also be expressed by equations of the form used for the solubility product, namely,

$\left(\mathrm{B}_{2} \mathrm{~A}\right)$ or $\left(\mathrm{A}_{2} \mathrm{~B}\right)=S_{\circ}\left(\Sigma_{i}\right) m_{u}$ or $\log \left[\left(\mathrm{B}_{2} \mathrm{~A}\right)\right.$ or $\left.\left(\mathrm{A}_{2} \mathrm{~B}\right)\right]=m_{u} \log \left(\Sigma_{i}\right)+\log \mathrm{S}_{\circ}$, where $S_{0}$ is the hypothetical concentration of the un-ionized part when the total ion concentration is zero. The values of the constants in these equations are given in Table XV.

The values of $m_{u}$ for barium iodate are inclosed in brackets, since certain assumptions were made in regard to the conductance of barium iodate solutions which make these results somewhat less reliable than the other. The values for thallium chloride are inclosed in parentheses to distinguish its values of $m_{u}$ from those for the unibivalent salts.

TABLE XV.-VALUes of $m^{u}, \Sigma i$, AND $S_{0}$, FOR THE UN-IONIZED PART OF SALTS IN SATURATED SOLUTIONS.

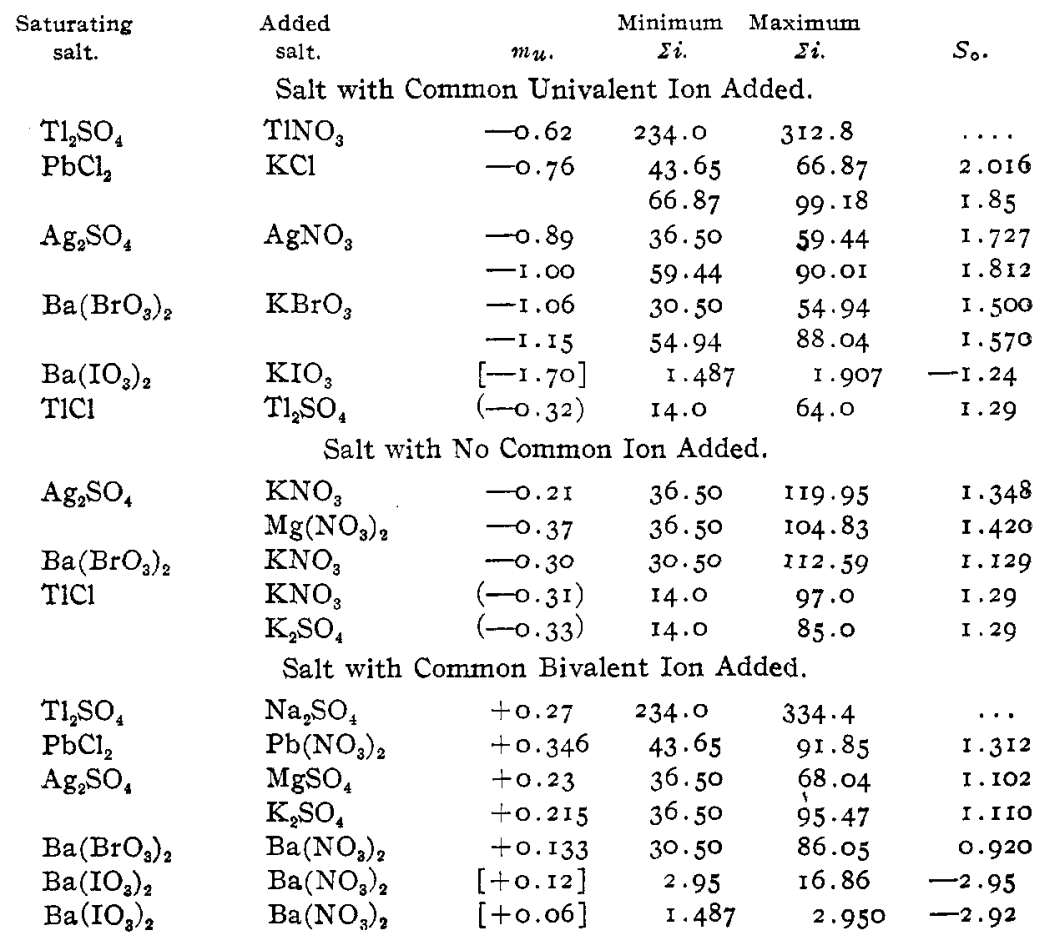

These values of $m_{u}$ indicate that the increase in the un-ionized concentration, when a salt with a common bivalent ion is added, becomes more normal as the solution becomes more dilute, while the decrease in that 
concentration produced by the addition of a salt with a common univalent ion seems to become more abnormal as the concentration of the solution decreases.

The change in the calculated values of the concentration of the un-ionized substance, as exhibited by Table XI, is so enormous, and the influence upon them of the various types of ions, as shown by Table XII, is so extraordinarily different, that it raises serious doubt as to whether they really represent that concentration at all-whether, in other words, they are not so affected by some deviation or superposed effect as to make them of little significance.

\section{Solubility Relations Shown by Expressing the Concentrations in} Terms of the Solubility in Pure Water.

Instead of carrying these calculations further at this point, it has seemed advizable to examin the existing solubility data by a different method. This method consists in making the equivalent solubility in pure water of the salt saturating the solution the unit for the measurement of all other concentrations. For the purpose of comparison, data on the solubility of uni-univalent salts have been included in this treatment.

Certain additional data taken from the literature are presented in Table XVI. In this table the column headed "Fractional conc. salt" gives the values of the ratio of the equivalent concentration of the added salt to the equivalent solubility of the saturating salt in pure water, while the column headed "Fractional solubility" gives the values of the ratio of the solubility of the salt in the salt solution to the solubility of the salt in water. All concentrations are expressed in milliequivalents per liter.

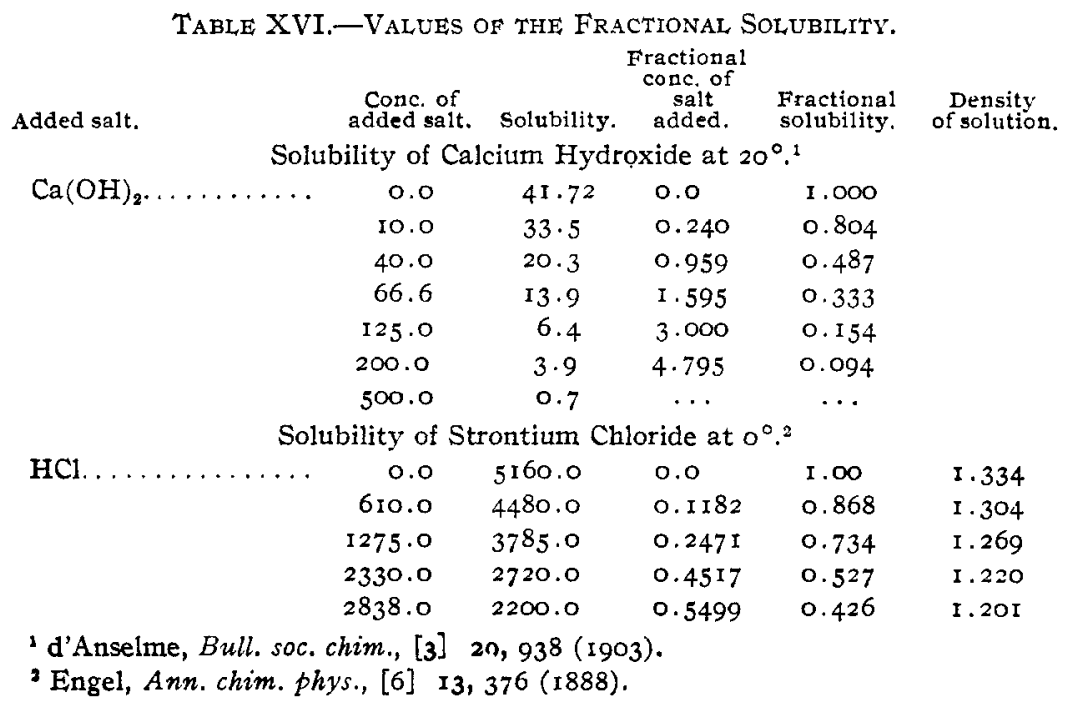


TABLE XVI (continued).

Added salt.

$\begin{array}{ccccc}\begin{array}{c}\text { Conc. of } \\ \text { added salt. }\end{array} & \begin{array}{c}\text { Solu- } \\ \text { bility. }\end{array} & \begin{array}{c}\text { Fractional } \\ \text { conc. of } \\ \text { salt added. }\end{array} & \begin{array}{c}\text { Fraetional } \\ \text { solubility. }\end{array} & \begin{array}{c}\text { Density } \\ \text { of solution. }\end{array} \\ 3725.0 & 1400.0 & 0.7220 & 0.271 & \text { I.167 } \\ 5275.0 & 6425.0 & 1.022 & 0.0824 & \text { I. } 133\end{array}$

Solubility of Sodium Chloride in Solutions of Hydrochloric Acid at $30^{\circ} .1$

\begin{tabular}{|c|c|c|c|c|c|}
\hline \multirow[t]{9}{*}{$\mathrm{HCl} \ldots \ldots \ldots \ldots \ldots$} & 0.0 & 5400.0 & 0.0 & 1.00 & I. 2018 \\
\hline & $457 \cdot 5$ & 4932.0 & 0.0488 & 0.914 & I. Ig06 \\
\hline & 969.0 & 4386.0 & o. I794 & 0.812 & $I .180 I$ \\
\hline & 1786.0 & 3589.0 & 0.3310 & 0.664 & I. I 633 \\
\hline & 2412.0 & 2978.0 & 0.4466 & $0.55^{2}$ & I. I 5 I 2 \\
\hline & 3052.0 & 2463.0 & 0.5656 & 0.456 & I. 1427 \\
\hline & 4152.0 & I 628.0 & $0.7^{692}$ & 0.301 & I. 1289 \\
\hline & 5950.0 & 630.0 & I. 102 & 0.1167 & I. I I 88 \\
\hline & 7205.0 & 268.0 & 1.335 & 0.0496 & I. $125^{8}$ \\
\hline
\end{tabular}

Solubility of Silver Propionate at $18.2^{\circ} .2$

Sodium propionate...

\begin{tabular}{|c|c|c|c|}
\hline 0.0 & 46.2 & 0.0 & 1.0 \\
\hline 16.7 & $39 \cdot 3$ & 0.3615 & $0.85 I$ \\
\hline $33 \cdot 3$ & $34 \cdot 5$ & $0.72 \mathrm{I}$ & 0.747 \\
\hline 66.7 & 25.8 & I. 444 & $0.55^{85}$ \\
\hline $133 \cdot 3$ & I9. I & 2.886 & 0.4137 \\
\hline 266.7 & 13.1 & $5 \cdot 7 \mathrm{I}$ & 0.2828 \\
\hline 500.0 & $10 . I$ & IO .82 & 0.2188 \\
\hline
\end{tabular}

Solubility of Silver Butyrate at $18.2^{\circ} .^{2}$

$\begin{array}{rrrll}\text { Sodium butyrate .... } & 0.0 & 22.4 & 0.0 & 1.0 \\ 6.6 & 19.9 & 0.2948 & 0.889 \\ 16.4 & 16.9 & 0.732 & 0.755 \\ 32.9 & 13.1 & 1.469 & 0.585 \\ 65.8 & .9 .1 & 2.94 & 0.4062 \\ & \text { I3I.5 } & 6.0 & 5.875 & 0.2679 \\ 263.0 & 4.0 & \text { r1 } 1.74 & 0.1785 \\ 493.0 & 2.7 & 22.01 & 0.1205\end{array}$

Solubility of Silver Chloroacetate at $16.9^{\circ} .^{2}$

$\begin{array}{lllll}\text { Sodium chloroacetate. } & 0.0 & 64.4 & 0.0 & 1.0\end{array}$

$\begin{array}{rlll}33.3 & 49.9 & 0.517 & 0.775 \\ 66.7 & 40.5 & 1.035 & 0.6295 \\ 133.3 & 29.9 & 2.07 & 0.4642 \\ 266.7 & 20.8 & 4.14 & 0.323 \\ 500.0 & 16.2 & 7.77 & 0.2518\end{array}$

Solubility of Silver Acetate at $16^{\circ} .^{2}$

$\begin{array}{rrrll}\mathrm{AgNO}_{3} \ldots \ldots \ldots \ldots . . & 0.0 & 60.3 & 0.0 & 1.0 \\ & 6 . \mathrm{I} & 4 \mathrm{I} .7 & 1.01 \mathrm{I} & 0.69 \mathrm{I} 6 \\ & 1 \mathrm{I} .9 & 34 . \mathrm{I} & 1.974 & 0.5656 \\ & 23.0 & 19.5 & 3.814 & 0.3234 \\ \mathrm{NaC}_{2} \mathrm{H}_{2} \mathrm{O}_{2} \ldots \ldots \ldots \ldots & 0.0 & 59.3 & 0.0 & 1.00 \\ & 33.3 & 47.4 & 0.562 & 0.798\end{array}$

${ }^{1}$ Masson, J. Chem. Soc., 99, I 132 (IgII).

${ }^{2}$ Arrhenius, $Z$. physik. Chem., $\mathrm{x}$ x, 396 (1893). For concentration of the un-ionized part see Stieglitz, This Journal, 29, I538 (1908). 
EFFECT OF SALTS UPON THE SOLUBILITY OF OTHER SALTS. VII. I 853

TABLE XVI (continued).

Added salt.

$\begin{array}{cccc}\begin{array}{c}\text { Conc. of } \\ \text { added salt. }\end{array} & \begin{array}{c}\text { Solu- } \\ \text { bility. }\end{array} & \begin{array}{c}\text { Fractional } \\ \text { conc. of } \\ \text { added salt. }\end{array} & \begin{array}{c}\text { Fractional } \\ \text { solubility. }\end{array} \\ 66.7 & 38.4 & 1.125 & 0.648 \\ 133.3 & 28.2 & 2.248 & 0.476 \\ 266.7 & 20.3 & 4.495 & 0.342 \\ 500.0 & 14.7 & 8.43 & 0.248\end{array}$

Solubility of Silver Valerate. ${ }^{1}$

$\mathrm{Na}$ valerate. ........

$\begin{array}{rccc}0.0 & 9.5 & 0.0 & \text { I.0 } \\ 17.5 & 4.7 & 1.84 & 4.95 \\ 34.9 & 3.0 & 3.67 & 3.16 \\ 68.9 & 1.8 & \ldots & \ldots \\ 139.5 & 1.5 & \ldots & \ldots\end{array}$

Solubility of Silver Bromate at $25^{\circ} .^{2}$

$\begin{array}{lllll}\mathrm{AgNO}_{3} \ldots \ldots \ldots \ldots \ldots & 0.0 & 8.10 & 0.0 & 1.0 \\ & 8.50 & 5.10 & 1.049 & 0.63 \\ & 34.60 & 2.16 & 4.272 & 0.267\end{array}$

Mean Solubility of $\mathrm{TlCl}$ in Solutions of $\mathrm{KCl}, \mathrm{NH}_{4} \mathrm{Cl}$ and $\mathrm{NaCl}$ at $25^{\circ} .2$

$\begin{array}{rrrll}\mathrm{KCl}, \mathrm{NH}_{4} \mathrm{Cl} \text { or } \mathrm{NaCl} . & 0.0 & \text { I6. I } 2 & 0.0 & 1.0 \\ 25.0 & 8.72 & 1.55 \mathrm{I} & 0.54 \mathrm{I} \\ 50.0 & 5.92 & 3.102 & 0.367 \\ 100.0 & 3.97 & 6.2 & 0.246 \\ 200.0 & 2.69 & \ldots & \ldots \\ 800.0 & 1.70 & \ldots & \ldots\end{array}$

Solubility of Thallium Chloride at $25^{\circ} .^{2}$

$\begin{array}{cccll}\mathrm{TlNO}_{3} \ldots \ldots \ldots \ldots \ldots & 0.0 & 16 . \mathrm{I} 2 & 0.0 & 1.0 \\ & 25.0 & 8.83 & \mathrm{I} .55 \mathrm{I} & 0.548 \\ & 50.0 & 6.26 & 3.102 & 0.388 \\ & 100.0 & 4.28 & 6.2 & 0.265 \\ & 0.0 & 16.07 & 0.0 & 1.0 \\ \mathrm{Tl}_{2} \mathrm{SO}_{4} \ldots \ldots \ldots \ldots & 19.99 & 10.34 & 1.243 & 0.643 \\ & 49.99 & 6.772 & 3.1 \mathrm{II} & 0.42 \mathrm{I} \\ & 99.97 & 4.679 & 6.22 & 0.29 \mathrm{I}\end{array}$

Solubility of Potassium Perchlorate at $25^{\circ} .^{3}$

\begin{tabular}{|c|c|c|c|c|}
\hline \multirow[t]{3}{*}{$\mathrm{KCl} \ldots \ldots \ldots \ldots$} & 0.0 & $148 . \mathrm{I}$ & 0.0 & I.O \\
\hline & $49 \cdot 73$ & I 28.2 & 0.336 & $0.86_{5}$ \\
\hline & $99 \cdot 33$ & I I 2.3 & 0.670 & $0.75^{8}$ \\
\hline \multirow{3}{*}{$\mathrm{K}_{2} \mathrm{SO}_{1} \ldots \ldots \ldots$} & 0.0 & I 48.1 & 0.0 & I.O \\
\hline & $49 \cdot 70$ & I 3 I. 5 & 0.336 & 0.887 \\
\hline & 99.22 & I I 8. I & 0.670 & 0.797 \\
\hline
\end{tabular}

Solubility of Barium Hydroxide. ${ }^{4}$

$\begin{array}{rrrll}\mathrm{Ba}\left(\mathrm{NO}_{3}\right)_{2} \ldots \ldots \ldots & 0.0 & 561.9 & 0.0 & 1.0 \\ 33.2 & 561.5 & 0.0581 & 0.999 \\ & 111.3 & 568.5 & 0.198 & \text { I.OII }\end{array}$

${ }^{1}$ Arrhenius, Loc. cit.

2 Noyes, Z. physik. Chem., 9, 629 (1892).

${ }^{3}$ Boggs, second article of this series, ThIs Journal, 33, $165^{2}$ (I9II).

- Parsons and Carson, This Journal, 32, 1383 (1910). Parsons and Perkins, Ibid., 32, 1387 . 
TABLE XVI (continued).

\begin{tabular}{|c|c|c|c|c|c|}
\hline \multirow[t]{8}{*}{ Added salt. } & $\begin{array}{c}\text { Conc. of } \\
\text { added salt. }\end{array}$ & $\begin{array}{l}\text { Solu. } \\
\text { bility. }\end{array}$ & $\begin{array}{l}\text { Fractional } \\
\text { conc. of } \\
\text { salt added. }\end{array}$ & $\begin{array}{l}\text { Fractional } \\
\text { solubility. }\end{array}$ & $\begin{array}{l}\text { Density } \\
\text { of solution. }\end{array}$ \\
\hline & 143.8 & $567 \cdot 5$ & 0.256 & I.009 & \\
\hline & 232.2 & 580.5 & 0.414 & $\mathrm{I} .032$ & \\
\hline & 338.2 & $587 \cdot 5$ & 0.602 & I. .045 & \\
\hline & 462.2 & 601.5 & 0.833 & $\mathrm{I} .069$ & \\
\hline & $533 \cdot 5$ & $6 \mathrm{II} \cdot 5$ & 0.950 & 1.088 & \\
\hline & 657.0 & $624 \cdot 5$ & I. I 70 & I. III & \\
\hline & $769 \cdot 5$ & 632.2 & I. 370 & I. 125 & \\
\hline \multicolumn{6}{|c|}{ Solubility of Strontium Nitrate. ${ }^{1}$} \\
\hline \multirow[t]{5}{*}{$\mathrm{Sr}(\mathrm{OH})_{2} \ldots \ldots \ldots$} & 0.0 & 6176.0 & 0.0 & I.O & \\
\hline & 60.6 & 6220.0 & 0.00982 & $\mathrm{I} .008$ & \\
\hline & 123.5 & 6270.0 & 0.0200 & 1.016 & \\
\hline & 279.0 & 6290.0 & 0.0454 & I.OIg & \\
\hline & \multicolumn{4}{|c|}{ Solubility of Barium Nitrate. ${ }^{1}$} & \\
\hline \multirow[t]{5}{*}{$\mathrm{Ba}(\mathrm{OH})_{2} \ldots \ldots \ldots$} & 0.0 & 772.0 & 0.0 & $\mathrm{I} . \mathrm{O}$ & \\
\hline & I98.7 & 802.0 & 0.257 & 1.038 & \\
\hline & 412.8 & 830.0 & 0.534 & I. 074 & \\
\hline & $645 \cdot 4$ & 866.0 & 0.836 & I. I 2 I & \\
\hline & \multicolumn{4}{|c|}{ Solubility of Thallium Sulfate. ${ }^{2}$} & \\
\hline \multirow{3}{*}{$\mathrm{Na}_{2} \mathrm{SO}_{4} \ldots \ldots \ldots$} & 0.0 & 216.8 & 0.0 & I.O & \\
\hline & 99.4 & 216.0 & 0.459 & 0.996 & \\
\hline & 397.6 & 234.6 & I. 834 & $\mathrm{I} .082$ & \\
\hline \multirow[t]{2}{*}{$\mathrm{NaHSO}_{4} \ldots \ldots \ldots \ldots$} & 0.0 & 216.8 & 0.0 & I.O & \\
\hline & 202.0 & 232.2 & 0.932 & 1.072 & \\
\hline \multirow[t]{3}{*}{$\mathrm{H}_{2} \mathrm{SO}_{4} \ldots \ldots \ldots \ldots$} & 0.0 & $2 \mathrm{I} 6.8$ & 0.0 & I. 0 & \\
\hline & 98.8 & 234.4 & 0.456 & $I .08 I$ & \\
\hline & 197.4 & 249.8 & 0.910 & I. I 52 & \\
\hline \multirow[t]{2}{*}{$\mathrm{Tl}\left(\mathrm{NO}_{3}\right)_{2} \ldots \ldots \ldots$} & 0.0 & 216.8 & 0.0 & I.O & \\
\hline & 99.6 & $167 \cdot 3$ & 0.460 & 0.772 & \\
\hline
\end{tabular}

The results of Table XVI, together with those presented in Papers V and VI of this series, are reproduced graphically in Fig. 4. The ordinates represent the "fractional solubility" of the dissolved salt, and the abscissas the "fractional concentration" of the added salt.

It will be seen that these curves, all of which represent the change of solubility caused by the addition of a salt with a common ion, fall into three groups, as follows:

I. The lowest group of curves showing the change of solubility of a uni-bivalent salt when the univalent common ion is added.

II. The middle group showing the effect of the addition of a salt with a common ion to a uni-univalent salt.

III. The highest group showing the effect of the addition of the common bivalent ion to a solution of a unibivalent salt.

${ }^{1}$ Parsons and Carson, Tris Journal, 32, 1383 (1910). Parsons and Perkins Ibid., 32, 1387.

${ }^{2}$ M. A. Stewart, paper II of this series, This Journal, 33, I66I (I9I I). 
The curves of Groups I and II lie close together, but those of Group III spread apart, forming a fan-shaped bundle. In each group the curves arrange themselves in general in the order of the solubilities of the salts in water, so that the greater the solubility the higher the curve. Exceptions in the case of very soluble salts will be considered later. Exceptions to this rule also occur in cases where the ionizations of the added salts are very different. Thus it will be seen that the curve for any given salt rizes to a higher position when the added salt is changed from one of a greater to one of a smaller ionization.

As the solubility of the salt decreases, the curves of any one group approach a lower limiting position, namely, that occupied by the theoretical curve for a salt of infinitesimal solubility or for a salt whose ionization is complete. The coördinates for these "theoretical limiting curves," designated T. L. C. in the figure, for the three groups were calculated by the following equations:

I. Unibivalent salt with univalent common ion added: $S(S+C)^{2}=1$.

II. Uni-univalent salt with univalent common ion added: $S(S+C)=\mathrm{r}$.

III. Unibivalent salt with bivalent common ion added: $S^{2}(S+C)=1$.

With the aid of the plot given in Fig. 4, the solubility in any dilute salt solution of any uni-univalent or unibivalent salt of moderate or slight solubility may be calculated with a fair degree of accuracy by taking into account its solubility in water and the valence types to which it and the added salt belong. As a secondary factor the degrees of ionization of both salts may be considered. The least accurate results will be obtained, in general, when the added salt contains a common bivalent ion. In this case the degree of ionization of the saturating salt must be taken into account. The writer calculated in this way the solubility of silver sulfate in 0.1 normal potassium sulfate, using principally the curves for barium bromate and thallous oxalate, and obtained the value 47.64 milliequivalents per liter while the true value is 48.04 . It would have been possible, by a different choice of the corrections, to have found a value as low as 46.57 . Even in this latter case the difference between the true and the calculated values is only r. 47 milliequivalents per liter, while the difference between the solubilities in water as determined by Drucker, and by the writer, amounts to 2.12 milliequivalents. Of course it cannot be expected that accurate results will be obtained in regions on the plot where the experimental values already obtained are scanty or inaccurate. Moreover, where the salt is so abnormal in all its solubility and ionization relations as lead chloride, such calculations will be much less accurate.

It is remarkable that the curves of Groups I and II lie so close to the curve for complete ionization (which has been called above the "theoretical limiting curve"). The curves of Group III, on the other hand, 


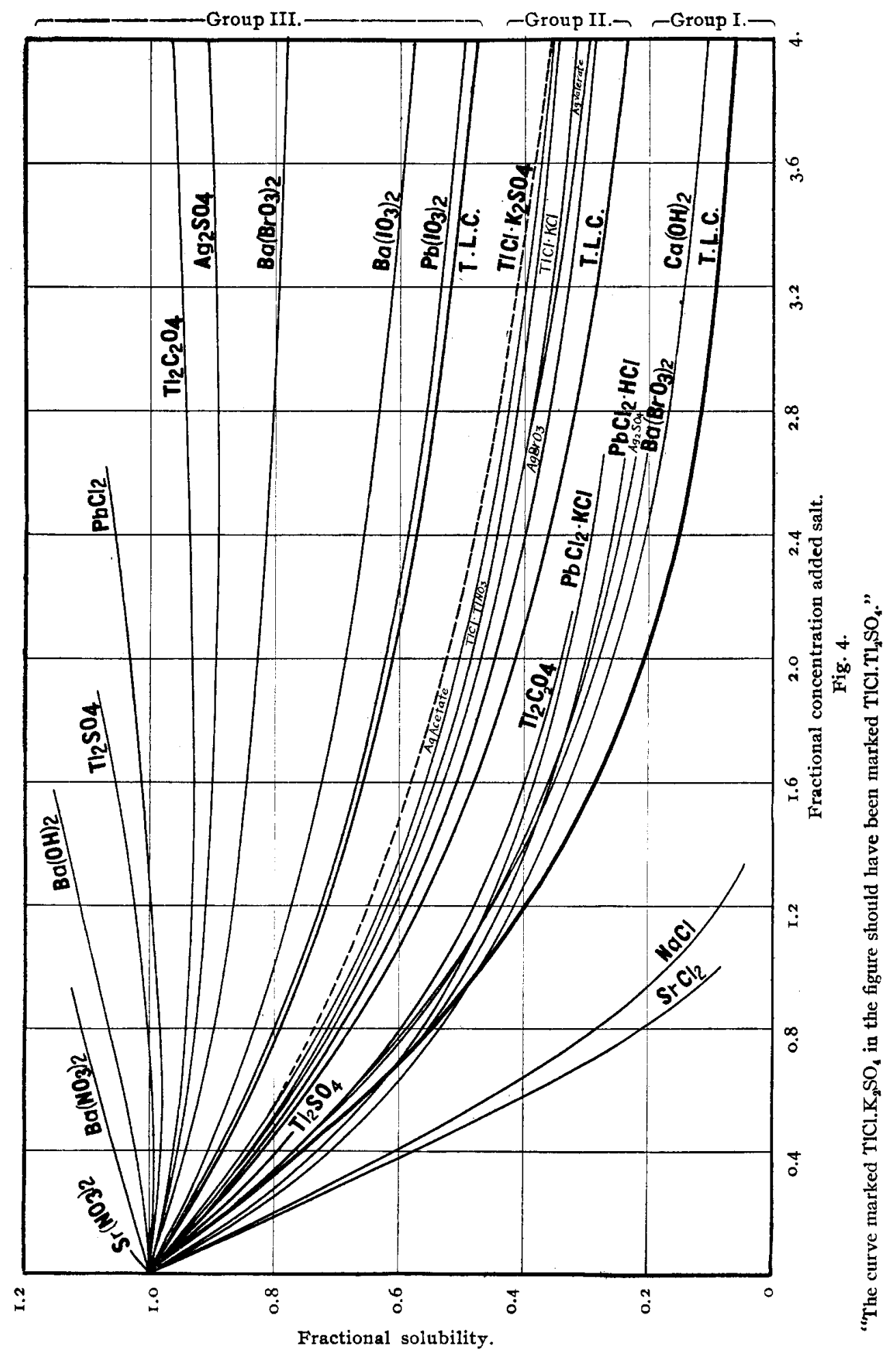




\begin{tabular}{|c|c|c|c|}
\hline & & Group I. & \\
\hline No. & Saturating salt. & Solubility. & Added salt. \\
\hline I. & $\mathrm{Ca}(\mathrm{OH})_{2} \ldots \ldots \ldots \ldots$ & 0.04172 & $\mathrm{NaOH}$ \\
\hline 2. & $\mathrm{Ba}\left(\mathrm{BrO}_{3}\right)_{2} \ldots \ldots \ldots \ldots \ldots$ & 0.04018 & $\mathrm{KBrO}_{3}$ \\
\hline 3. & $\mathrm{Ag}_{2} \mathrm{SO}_{4} \ldots \ldots \ldots \ldots \ldots$ & 0.05352 & $\mathrm{AgNO}_{3}$ \\
\hline 4. & $\mathrm{PbCl}_{2} \ldots \ldots \ldots \ldots \ldots \ldots$ & $0.0777^{6}$ & $\mathrm{KCl}$ \\
\hline 5. & $\mathrm{PbCl}_{2} \ldots \ldots \ldots \ldots \ldots$ & 0.07776 & $\mathrm{KCl}$ \\
\hline 6. & $\mathrm{Tl}_{2} \mathrm{C}_{2} \mathrm{O}_{4} \ldots \ldots \ldots \ldots \ldots$ & 0.07536 & $\mathrm{TINO}_{3}$ \\
\hline 7. & $\mathrm{Tl}_{2} \mathrm{SO}_{4} \ldots \ldots \ldots \ldots \ldots$ & 0.2166 & $\mathrm{TiNO}_{3}$ \\
\hline$* 8$ & $\mathrm{SrCl}_{2} \ldots \ldots \ldots \ldots \ldots \ldots$ & $5 \cdot 16$ & $\mathrm{HCl}$ \\
\hline & & Group II. & \\
\hline I. & $\mathrm{AgBrO}_{3} \ldots \ldots \ldots \ldots \ldots$ & 0.00810 & $\mathrm{AgNO}_{3}$ \\
\hline 2. & Ag valerate.............. & $0.0095^{\circ}$ & $\mathrm{Na}$ valerate \\
\hline 3. & Ticl $\ldots \ldots \ldots \ldots \ldots \ldots$ & 0.01612 & $\mathrm{KCl}$ \\
\hline 5. & $\mathrm{~T} 1 \mathrm{Cl} \ldots \ldots \ldots \ldots \ldots \ldots$ & 0.01612 & $\mathrm{TINO}_{3}$ \\
\hline 6. & Ag butyrate. $\ldots \ldots \ldots \ldots \ldots$ & 0.0224 & Na butyrate \\
\hline 7. & Ag propionate........... & 0.0462 & Na propionate \\
\hline $8 .^{2}$ & $\mathrm{KClO}_{4} \ldots \ldots \ldots \ldots \ldots$ & o. $148 \mathrm{I}$ & $\mathrm{KCl}$ \\
\hline 9. & $\mathrm{Ag}$ acetate $\ldots \ldots \ldots \ldots$ & 0.0603 & $\mathrm{Na}$ acetate \\
\hline Io. & $\mathrm{TiCl} \ldots \ldots \ldots \ldots \ldots \ldots$ & 0.01612 & $\mathrm{Tl}_{2} \mathrm{SO}_{4}$ \\
\hline *II. & $\mathrm{NaCl} \ldots \ldots \ldots \ldots \ldots \ldots$ & $5 \cdot 40$ & $\mathrm{HCl}$ \\
\hline & & Group III. & \\
\hline I. & $\mathrm{Pb}\left(\mathrm{IO}_{3}\right)_{2} \ldots \ldots \ldots \ldots \ldots$ & 0.0001102 & $\mathrm{~Pb}\left(\mathrm{NO}_{3}\right)_{2}$ \\
\hline 2. & $\mathrm{Ba}\left(\mathrm{IO}_{3}\right)_{2} \ldots \ldots \ldots \ldots \ldots$ & 0.001579 & $\mathrm{Ba}\left(\mathrm{NO}_{3}\right)_{2}$ \\
\hline 3. & $\mathrm{Ba}\left(\mathrm{BrO}_{3}\right)_{2} \ldots \ldots \ldots \ldots$ & 0.04018 & $\mathrm{Ba}\left(\mathrm{NO}_{3}\right)_{2}$ \\
\hline 4. & $\mathrm{Ag}_{2} \mathrm{SO}_{4} \ldots \ldots \ldots \ldots \ldots$ & $0.0535^{2}$ & $\mathrm{~K}_{2} \mathrm{SO}_{4}$ \\
\hline 5. & $\mathrm{Tl}_{2} \mathrm{C}_{2} \mathrm{O}_{4} \ldots \ldots \ldots \ldots$ & 0.07536 & $\mathrm{~K}_{2} \mathrm{C}_{2} \mathrm{O}_{4}$ \\
\hline 6. & $\mathrm{PbCl}_{2}, \ldots \ldots \ldots \ldots \ldots$ & 0.07776 & $\mathrm{~Pb}\left(\mathrm{NO}_{3}\right)_{2}$ \\
\hline 7.. & $\mathrm{Tl}_{2} \mathrm{SO}_{4} \ldots \ldots \ldots \ldots \ldots \ldots \ldots$ & 0.2168 & $\mathrm{Na}_{2} \mathrm{SO}_{4}$ \\
\hline 8. & $\mathrm{Ba}(\mathrm{OH})_{2} \ldots \ldots \ldots \ldots \ldots$ & 0.562 & $\mathrm{Ba}\left(\mathrm{NO}_{2}\right)_{2}$ \\
\hline 9. & $\mathrm{Ba}\left(\mathrm{NO}_{3}\right)_{2} \ldots \ldots \ldots \ldots$ & 0.772 & $\mathrm{Ba}(\mathrm{OH})_{2}$ \\
\hline 10. & $\mathrm{Sr}\left(\mathrm{NO}_{3}\right)_{2} \ldots \ldots \ldots \ldots \ldots$ & 6.176 & $\mathrm{Sr}(\mathrm{OH})_{2}$ \\
\hline
\end{tabular}

The preceding table serves to show that the added salt was in the case of each of the curves represented in Fig. 4 , and also to indicate the magnitude of the absolute solubility of each of the saturating salts. The arrangement of the substances in the table (except in the two cases of the very readily soluble salts, sodium chloride and strontium chloride, distinguished by an asterisk) has been made to correspond to the relative positions of the curves on the diagram. How nearly this order corresponds with that of the solubilities of the salts will be readily seen from the column of the table headed "solubility."

1 The curves for all of the cases listed were drawn in the original drawing, but on account of the reduction of the size of the drawing in the cut, some of the curves for Class 2 have been omitted, but their position is indicated by the order in which the salts are here tabulated.

${ }^{2} \mathrm{Only}$ one point has been determined for $\mathrm{KClO}_{4}$, and this lies slightly below the curve for silver acetate though the latter has the smaller solubility; this may be due either to an error in the determination of the solubility of the $\mathrm{KClO}_{4}$, or to the same cause which so greatly lowers the $\mathrm{NaCl}$ curve. 
deviate widely from the theoretical curve and from each other. Thus, the solubility of the easily soluble salts strontium nitrate and barium nitrate increases from the beginning with increasing concentration of the added salt when this contains a common bivalent ion. The curves for these substances have therefore the general form of the curves representing the effect of adding a salt with no common ion. The solubility of the less soluble salts, thallous sulfate and lead chloride, decreases with the first addition of a salt with a common bivalent ion, but increases on further additions.

The least soluble salt which had been investigated when Fig. 3 was first drawn was barium bromate. The curve for this salt falls considerably at first and then continues to fall slowly up to a concentration of 0.2 normal for the added salt. It has therefore the general form of the theoretical limiting curve, but it still lies very far above it. It was predicted that the curve for barium iodate would lie about two-thirds closer to the theoretical limiting curve, and that the curve for lead iodate would approach much closer still, and this was found to be true when the solubilities of these salts were determined.

Fig. 3 shows that the solubility of unibivalent salts of moderate or slight solubility is decreased to about $5^{\circ}$ per cent. by the addition of an equivalent amount of a salt with a common univalent ion. When the saturating salt is uni-univalent the solubility is decreased to about 65 per cent. of that in water, and when a salt with a common bivalent ion is added to a saturated unibivalent salt solution the maximum decrease to be expected is to 75.4 per cent. of the original value.

It will be noted that certain of the experimental curves, all belonging to Group I, fall below the theoretical limiting curves for small additions of the common univalent ion. This is true of the curves for lead chloride in the presence of hydrochloric acid and potassium chloride, and that for calcium hydroxide in the presence of sodium hydroxide. The cause of this phenomenon will be discussed below, in Section 24 .

\section{The Solubility of Extremely Soluble Salts in Salt Solutions.}

It is not the purpose of this paper to consider fully the solubility of very soluble salts, since the writer is now preparing a separate paper on this subject, and since the data are not at present in such shape as to make it safe to generalize. It is, however, worth while at this point to note the fact clearly brought out by the experiments of Engel ${ }^{1}$ and Masson $^{2}$ that the solubility of many very soluble salts is reduced with great rapidity by the addition of acids and of salts which contain a common ion. Engel explains this great decrease in solubility by assuming that the water is partitioned between the salts. It does not seem to have been recognized, however, that the solubility relations in these con-

'Ann. chim. phys., [6] I3, 376 (1888).

${ }^{2} \mathrm{~J}$. Chem. Soc., 99,1132 (1911). 
centrated solutions may be classified according to the types of the saturating and added salts. For salts with a solubility of about one equivalent per liter, the classification into the three groups seems to persist, though the curves for Groups I and II fall below the theoretical limiting curves. Where the solubility is much higher, it becomes impossible to distinguish between the curves of Groups I and II, which fall with extreme rapidity. When a salt with a common bivalent ion is added, the solubility curves (Group III) for every case yet investigated rize as the concentration of the added salt increases. ${ }^{2}$ It is quite possible, however, that a decrease could be found in solutions where the added salt has a sufficiently high concentration, since, even when a salt with no common ion is added, there seems to be a tendency for the solubility to decrease under such conditions.

The curves for one very soluble salt for each of Groups I and II have been included in Fig. 4 for the purpose of comparison. It is evident that if we begin with very difficultly soluble salts, the curves rize farther and farther above the theoretical limiting curves as the solubility of the salt increases, until that solubility attains a fairly high value, but then as the solubility increases still further the change in solubility becomes negative, and the curves fall, even very far below the position of the theoretical limiting curve.

\section{Theoretical Explanation of the Irregular Solubility Relations of Uni- bivalent Salts by the Intermediate Ion Hypothesis.}

The calculations of this paper have shown that there are certain fairly definit regularities governing the solubility product of unibivalent salts, but scarcely any relating to the concentration of the unionized part. It has, moreover, been seen that these salts exhibit great deviations not only from the theoretical requirements, but also from the more regular behavior of uni-univalent salts. These deviations are, however, so consistent among themselves that it seems evident that they are due to some common cause.

One especially significant fact is that when a salt with a common bivalent ion is added to a very soluble salt of the unibivalent type, the curve has the same form as that representing the effect of the addition of a salt with no common ion. Therefore, the theoretical explanation required would seem to be one which would account for this change from the theoretical form of the curve for difficultly soluble salts in very dilute solutions to this entirely different form in the concentrated solutions. The most obvious assumption is that, as the concentration of

${ }^{2}$ Etard (Ann. chim. phys., [7] 2, 540 (1894)) gave what is possibly an exception to this rule. He finds that the solubility of barium bromide is greatly reduced, and that of barium iodide slightly reduced, each by the presence of the other salt in the solution. 
the solution increases, there is some chemical reaction taking place by which a considerable amount of some new substance is formed by combination of the ions present in the solution.

While the un-ionized concentration of a uni-univalent salt in saturated solution decreases at about the same rate with the increase in total ion concentration whatever be the type of the added salt, the case is very different when the saturating salt is unibivalent. In the latter case the addition of a salt with a common univalent ion always decreases the calculated concentration of the unionized part very much more rapidly than the addition of a salt with no common ion. It is difficult to see why the addition of silver nitrate should cause a depression in concentration of the un-ionized part of silver sulfate so much greater than that produced by potassium nitrate or magnesium nitrate; or why potassium bromate should cause a decrease in the concentration of the un-ionized part of barium bromate which is so much greater than that produced by potassium nitrate. When we turn to the rapid increase in the concentration of the un-ionized part caused by the addition of a salt with a common bivalent ion, we again find a result of the calculations which seems equally unreasonable. Such results cast serious doubts upon the significance of the calculated values of the un-ionized concentration. The most obvious explanation of them seems to be that a part of what we have considered to be the un-ionized substance is in reality the intermediate ion, such as $\mathrm{AgSO}_{4}^{-}$or $\mathrm{NO}_{3} \mathrm{Ba}^{+}$.

The possibility that intermediate ions exist in aqueous solutions of unibivalent salts has frequently been suggested in the literature, but has really received little serious consideration. In fact the authors who favor the assumption of intermediate ions have usually postulated a specific intermediate ion in order to account for some specific experimental result. Thus Abegg and Spencer, ${ }^{1}$ in considering the solubility of thallous oxalate, assume that it gives rise to an intermediate ion, but that potassium oxalate does not. In the same way in a recent paper, Jellinek ${ }^{2}$ concludes from calculations in regard to the freezing point that intermediate ions are present in sodium sulfate solutions, but not in potassium sulfate solutions.

It appears to the author highly probable that all unibivalent salts yield intermediate ions in not far from the same proportion at the same concentration if they are present in any of them; and it is his purpose to show that this hypothesis will explain in a general way the solubility relations of such salts, especially the abnormal increase in the solubility product, the extraordinary decrease in the calculated concentration of

1Z. anorg. Chem., 46, 406 (1905).

'Z. physik. Chem., 76, 309 (1911). 
the un-ionized part caused by the common univalent ion, and the peculiar effect of the common bivalent ion.

It may first be shown that it suggests an explanation of the increase produced in the solubility of very soluble salts by the addition of a salt with a common bivalent ion. Thus, the saturated solution of strontium nitrate (see curve in Fig. 4), which is about 6-normal, must have a large concentration of $\mathrm{SrNO}_{4}{ }^{+}$ions and $\mathrm{NO}_{3}{ }^{-}$ions, but only a very small concentration of $\mathrm{Sr}^{++}$ion. When strontium hydroxide is added to it, the ions which it brings into the solution are largely $\mathrm{SrOH}^{+}$and $\mathrm{OH}^{-}$. As the amount of the common $\mathrm{Sr}^{++}$ion introduced is small, the decrease of the concentration of the $\mathrm{NO}_{3}{ }^{-}$ion is small, and this effect is overcompensated by the amount of un-ionized $\mathrm{Sr}(\mathrm{OH}) \mathrm{NO}_{3}$ formed by the combination of the $\mathrm{SrNO}_{3}{ }^{+}$with the $\mathrm{OH}^{-}$.

In the case of salts of moderate solubility, the main effect of the intermediate ion of the salt saturating the solution on the solubility will be that caused by the change in the proportion of this ion present, rather than that caused by the change in the formation of the un-ionized substance (such as $\operatorname{Sr}(\mathrm{OH}) \mathrm{NO}_{3}$ ). There will be the further effect, when a salt with the common bivalent ion is added, of the intermediate ion of this added salt, which effect will consist in reducing the quantity of the bivalent ion which that salt brings into the solution. The direction of these effects can be predicted by formulating the mass-action equations as follows: Consider a salt $A_{2} B$ which ionizes into the simple ions $A^{+}$ or $\mathrm{A}^{-}$and $\mathrm{Ba}^{=}$or $\mathrm{B}^{++}$and in to the intermediate ion $\mathrm{AB}^{-}$or $\mathrm{AB}^{+}$. Let its molal solubility be $S_{0}$ in pure water, $S_{1}$ in the presence of another salt .AC with the common univalent ion $\mathrm{A}^{+}$or $\mathrm{A}^{-}$, and $S_{2}$ in the presence of another salt $\mathrm{D}_{2} \mathrm{~B}$ with the common bivalent ion $\mathrm{B}^{=}$or $\mathrm{B}^{++}$and the intermediate ion $\mathrm{DB}^{-}$or $\mathrm{DB}^{+}$. Representing the molal concentrations of the constituents of the salt in the first solution by $\left(A_{2} B\right)_{0},(A)_{0},(B)_{0}$, and $(A B)_{0}$, and in the second and third solutions by $\left(A_{2} B\right)_{1}$ and $\left(A_{2} B\right)_{2}$, $(A)_{1}$ and $(A)_{2}$, etc., the following equations express the solubility principles $^{1}$ and the conditions of the problem:

$$
\begin{gathered}
\left(\mathrm{A}_{2} \mathrm{~B}\right)_{0}=\left(\mathrm{A}_{2} \mathrm{~B}\right)_{1}=\left(\mathrm{A}_{2} \mathrm{~B}\right)_{2} . \\
(\mathrm{A})_{0}(\mathrm{AB})_{0}=(\mathrm{A})_{1}(\mathrm{AB})_{1}=(\mathrm{A})_{2}(\mathrm{AB})_{2} . \\
(\mathrm{A})_{0}{ }^{2}(\mathrm{~B})_{0}=(\mathrm{A})_{1}{ }^{2}(\mathrm{~B})_{1}=(\mathrm{A})_{2}{ }^{2}(\mathrm{~B})_{2} . \\
S_{0}=\left(\mathrm{A}_{2} \mathrm{~B}\right)_{0}+(\mathrm{AB})_{0}+\left(\mathrm{B}_{0}\right), \text { and } S_{1}=\left(\mathrm{A}_{2} \mathrm{~B}\right)_{1}+(\mathrm{AB})_{1}+(\mathrm{B})_{1}
\end{gathered}
$$

1 Judging from the results with uni-univalent salts, the second and probably the third of these solubility principles may be expected to hold true approximately. The first principle, stating the constancy of the un-ionized concentration, is doubtless considerably in error; but the influence of this error on the result is comparatively slight, since that concentration forms a very small part of the total concentration. Its influence, so far as it goes, causes the decrease of solubility to be somewhat greater than that calculated from equations (6) and (7). 


$$
\text { or } \begin{aligned}
2 S_{0}=2\left(\mathrm{~A}_{2} \mathrm{~B}\right)_{0}+(\mathrm{AB})_{0}+(\mathrm{A})_{0} \text {, and } \\
\qquad 2 S_{2}=2\left(\mathrm{~A}_{2} \mathrm{~B}\right)_{2}+(\mathrm{ADB})_{2}+(\mathrm{AB})_{2}+(\mathrm{A})_{2} .
\end{aligned}
$$

By combining these equations we obtain the following expressions for the fractional decrease in solubility produced by increasing the concentration of the univalent ion from $(A)_{0}$ to $(A)_{1}$ and by increasing that of the bivalent ion from $(B)_{\circ}$ to $(B)_{2}$ :

$$
\begin{gathered}
S_{0}-S_{1}=\frac{(\mathrm{A})_{1}-(\mathrm{A})_{0}}{(\mathrm{~A})_{1}}\left[(\mathrm{~B})_{0}\left(\mathrm{I}+\frac{(\mathrm{A})_{0}}{(\mathrm{~A})}\right)+(\mathrm{AB})_{0}\right] \\
2\left(S_{0}-S_{2}\right)=\frac{(\mathrm{B})_{2}^{1 / 2}-(\mathrm{B})_{0}^{\mathrm{T} / 2}}{(\mathrm{~B})_{0}^{1 / 2}}\left[(\mathrm{~A})_{0}\left(\frac{(\mathrm{B})_{0}}{(\mathrm{~B})_{2}}\right)^{\mathrm{I} / 2}-(\mathrm{AB})_{0}\right]-(\mathrm{ADB})_{2}
\end{gathered}
$$

From these equations the following conclusions may be drawn:

(I) The opposit signs of the term $(A B)$, in the two expressions show that the intermediate ion $\mathrm{AB}$ would exert an opposit effect on the solubility, according as the concentration of the univalent ion or that of the bivalent ion is increased. In the former case it causes the decrease of solubility to be larger, and in the latter case to be smaller, than it would be if this intermediate ion were not present. In the latter case the intermediate ion $\mathrm{DB}$ also causes the decrease to be smaller, first, because of the effect of the negative term $(\mathrm{ADB})_{2}$, and secondly, because for a given concentration of the added salt, $(B)_{2}$ is smaller the larger the proportion of DB present.

(2) The solubility relations of a slightly soluble salt to which a salt with the common univalent ion $\mathrm{A}$ is added would not be much affected by the intermediate ion, since in this case $(A B)_{0} /(B)_{0}$ is small. This would still be true even when the concentration of the ion $A$ is greatly increased, since the factor $\left(\mathrm{I}+\frac{(\mathrm{A})_{0}}{(\mathrm{~A})_{1}}\right)$, by which $(\mathrm{B})_{0}$ is multiplied, can only vary between the limiting values 2 and $I$.

(3) The solubility relations of a slightly soluble salt to which a salt with the common bivalent ion $\mathrm{B}$ is added will not be much affected by the intermediate ion $\mathrm{AB}$ so long as the concentration $(B)_{2}$ of the bivalent ion is not greatly increased, since in that case the ratio of $(A B)$ oto $(\mathrm{A})_{0}(\mathrm{~B})_{0}^{1 / 2} /(\mathrm{B})_{2}{ }^{1 / 2}$ is small. If, however, the concentration of the bivalent ion be greatly increased, so that the latter term becomes small, the decrease of solubility may be considerably less than it would be if the intermediate ion were not present, even with a slightly soluble salt. The intermediate ion DB will also diminish the decrease of solubility more and more as the concentration of the added salt increases, owing to the larger proportion of the un-ionized substance ADB formed.

(4) In the case of moderately soluble salts the decrease of solubility caused by adding a salt with the common bivalent ion will pass over into an increase when the concentration of the added salt is moderately increased, 
for the ratio $(A B)_{0} /(A)_{0}$ is in this case fairly large and the negative term $(A B)$, within the bracket will soon compensate the steadily decreasing positive term containing $(A)$ oto such an extent that the whole second member of equation (7) becomes negative, and this all the more since the negative term $(\mathrm{ADB})_{2}$ is also increasing.

(5) In the case of readily soluble salts to which a salt with the common bivalent ion is added, the first addition may cause an increase of solubility, for in a case where $(A B)_{0} /(A)_{0}$ is sufficiently large, the two negative terms may exceed the positive one, even when the factor of the latter (B) ${ }_{0}^{1 / 2} /(\mathrm{B})_{2}{ }_{2}^{1 / 2}$ is equal to unity.

(6) In the preceding statements about the different effects with salts of different solubility, it is assumed that there is a parallelism between the solubility and the proportion of the intermediate ion $A B$ present. If in any special case this ion is present in larger proportion than usual, the salt will behave like one of higher solubility with normal ionization. (This seems to be true of lead chloride (and probably of lead iodate also), whose solubility. is decreased much less than the usual amount by the addition of the common bivalent ion $\left(\mathrm{Pb}^{++}\right)$, and much more than the usual amount by the addition of the common univalent ion $\left.\left(\mathrm{Cl}^{-}\right).\right)^{1}$ It seems also to be true of calcium hydroxide.

A reference to the discussion in the preceding sections will show that the experimental results are in full accord with all these conclusions, and that they furnish illustrations of each one of them. The intermediateion hypothesis gives therefore a remarkably satisfactory explanation of these solubility phenomena from a qualitative or directional standpoint.

From a quantitative standpoint it is not possible to treat the matter very satisfactorily, owing to lack of knowledge of the proportions in which the intermediate ion and the simple ions are present. It seems worth while, however, to show that there are certain probable approximate assumptions which enable an estimate of these proportions to be made, and to illustrate by one or two examples the effect on the solubility relations of taking into account the presence of a considerable proportion of the intermediate ion.

There are two assumptions which seem to afford the best basis for estimating the proportions of the constituents in solutions of uni-bivalent salts. The first of these is the assumption that the principle that different salts of the same valence type have approximately the same ionization values, or more properly the same ionization constants, ${ }^{2}$ applies to the

${ }^{1}$ When the curves representing the effect upon the solubility of lead iodate of adding potassium lodate was plotted on the drawing used in making Fig. 4, it was found that this curve fell considerably below the electrical limiting curve. It should be noted that these curves fall below the theoretical limiting curve only when the total ion concentration is small.

${ }^{2}$ Noyes, This Journal, 30, 35 I (I908). 
first stage of the ionization of unibivalent salts. Thus if a salt $A_{2} B$ (such as $\mathrm{Ag}_{2} \mathrm{SO}_{4}$ ) ionizes at first into $\mathrm{A}^{+}+\mathrm{AB}^{-}$, it ionizes as a uni-univalent salt, and should therefore be about 83 per cent. ionized in this way in 0.1 normal solution.

The second assumption is based on the fact that the transference numbers of unibivalent salts (excluding the halides of bivalent metals) vary scarcely at all with the concentration. It is a necessary consequence of this fact ${ }^{1}$ that the intermediate ion, if it be present in considerable quantity, have an equivalent conductance equal to $\Lambda_{A} \Lambda_{B} /\left(2 \Lambda_{A}+\Lambda_{B}\right)$, where $\Lambda_{A}$ and $\Lambda_{B}$ are the equivalent conductances of the simple univalent and bivalent ions of a salt $\mathrm{A}_{2} \mathrm{~B}^{2}$ Thus in the case $\circ \mathrm{K}_{2} \mathrm{SO}_{4}$, where $\Lambda_{\mathrm{K}}+$ is approximately equal to $\Lambda_{\mathrm{SO}_{4}}=, \Lambda_{\mathrm{HSO}_{4}^{-}}$is nearly equal to ${ }^{1} /{ }_{3} \Lambda_{\mathrm{K}^{+}}$.

Calculations of the concentration of the constituents in silver sulfate solutions were made by the writer, and in potassium sulfate solutions by Prof. W. C. Bray. The method used was to calculate by a method of approximations the concentrations of the constituents which under the

TABLE XVII.-CONCENTRations OF the Constituents In Solutions OF UNIBIVALENT Salts Calculated under Certain Assumptions as to the INTERmediate ION.

Silver Sulfate.

\begin{tabular}{|c|c|c|c|}
\hline \multirow{2}{*}{\multicolumn{4}{|c|}{0.05352}} \\
\hline & & & \\
\hline Conc. $\mathrm{Ag}=\Sigma i \ldots \ldots \ldots \ldots \ldots$ & 0.00878 & 0.0403 & 0.0702 \\
\hline $\mathrm{AgSO}_{4} \ldots \ldots \ldots \ldots \ldots \ldots \ldots$ & 0.00107 & 0.01004 & 0.02186 \\
\hline so $_{1}=\ldots \ldots \ldots \ldots \ldots \ldots$ & 0.00385 & 0.01513 & $0.024 I^{2}$ \\
\hline $\mathrm{Ag}_{2} \mathrm{SO}_{4} \ldots \ldots \ldots \ldots \ldots \ldots$ & 0.000077 & 0.001596 & 0.00397 \\
\hline$k_{1}=\left(\mathrm{Ag}^{+}\right)\left(\mathrm{NO}_{3}^{-}\right) /\left(\mathrm{AgNO}_{3}\right) \ldots$ & 0.123 & 0.254 & $0.33^{6}$ \\
\hline $\begin{array}{l}k_{2}=\left(\mathrm{Ag}^{+}\right)\left(\mathrm{SO}_{4}=\right) /\left(\mathrm{AgSO}_{4}\right) \ldots \ldots \\
\text { Per cent. sulfate as }\end{array}$ & 0.0316 & 0.0608 & $0.077^{6}$ \\
\hline $\mathrm{AgSO}_{4}^{-} \ldots \ldots \ldots \ldots \ldots \ldots \ldots$ & $2 \mathrm{I} \cdot 4$ & $37 \cdot 5$ & $43 \cdot 7$ \\
\hline $\mathrm{SO}_{4}=\ldots \ldots \ldots \ldots \ldots \ldots$ & $77 \cdot 0$ & 56.5 & $48 \cdot 3$ \\
\hline$\ldots \ldots \ldots \ldots \ldots$ & I. 54 & $5 \cdot 97$ & $7 \cdot 94$ \\
\hline \multicolumn{4}{|c|}{ Potassium Sulfate. } \\
\hline Equiv, conc. as salt $\ldots \ldots \ldots \ldots$ & 0.01 & 0.10 & 1.00 \\
\hline Conc. $\mathrm{K}=\Sigma i, \ldots \ldots \ldots \ldots$ & 0.0090 & 0.0774 & 0.62 \\
\hline $\mathrm{KSO}_{4} \ldots \ldots \ldots \ldots \ldots \ldots \ldots$ & 0.0009 & 0.0176 & 0.25 \\
\hline$\ldots \ldots \ldots \ldots \ldots$ & 0.00405 & 0.0299 & 0.185 \\
\hline $\mathrm{K}_{2} \mathrm{SO}_{4} \ldots \ldots \ldots \ldots \ldots \ldots \ldots$ & 0.00005 & 0.0025 & 0.165 \\
\hline$k_{1}=\left(\mathrm{K}^{+}\right)\left(\mathrm{Cl}^{-}\right) /(\mathrm{KCl}) \ldots \ldots \ldots$ & 0.150 & 0.533 & $2 \cdot 32$ \\
\hline $\begin{array}{l}k_{2}=\left(\mathrm{K}^{+}\right)\left(\mathrm{SO}_{4}=\right) /\left(\mathrm{KSO}_{4}^{-}\right) \ldots \ldots \\
\text { Per cent. sulfate as }\end{array}$ & 0.040 & 0.132 & 0.46 \\
\hline $\mathrm{KSO}_{4}^{-} \ldots \ldots \ldots \ldots$ & 18.0 & $35 \cdot 2$ & 46.0 \\
\hline $\mathrm{SO}_{4}=\ldots$ & $8 \mathbf{r} \cdot 0$ & 59.8 & 42.0 \\
\hline$\ldots \ldots \ldots \ldots \ldots \ldots$ & I.O & 5.0 & 12.0 \\
\hline
\end{tabular}

${ }^{1}$ Falk, This Journal, 32, 1569 (1910). Noyes and Falk, Ibid., 33, 1443 (1911).

2 Lewis (THIS JoURNaL, 32, 1569 (I9II) (footnote)) has shown that this follows from the hypothesis that the frictional resistance to the motion of the intermediate ion $A B$ is equal to the sum of the resistances to the motion of the two constituent ions $A$ and $B$. 
assumptions just stated cause the calculated specific conductance of the solution in each case to be the same as that experimentally determined. The results are given in Table XVII.

It will be seen from this table that the proportion of intermediate ion increases rapidly with increasing concentration. The most striking result, however, is that $k_{2}$, the ionization function for the second stage of ionization, increases with increasing ion concentration, and is nearly proportional to $k_{1}$. Since the latter is related to the total ion concentration $(\Sigma i)$ by the general equation which holds for diionic salts, $k_{1}=$ $K(\Sigma i)^{2-n}$, where $K$ is a constant, it follows that $k_{2}$ must obey a similar law, though the exponent $(2-n)$ will probably be somewhat different in the two cases. This uniformity in the functions may be regarded as a confirmation of the assumptions upon which the calculations were based.

Calculations were then made of the concentrations of the constituents in a o. I normal silver nitrate solution and in o. I normal potassium sulfate solution saturated with silver sulfate. The results are given in Tables XVIII and XIX:

Table XVIII.-Concentration of the Constituents in Solutions Saturated WITH SILVER SULFATE.

\begin{tabular}{|c|c|c|c|c|c|c|c|c|}
\hline 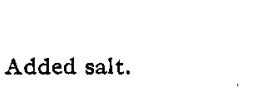 & $\begin{array}{c}\text { Total } \\
\mathrm{Ag}_{2} \mathrm{SO}_{4}\end{array}$ & $\sigma 8$ & $\lg +$ & $D_{4}=$ & os & $\begin{array}{l}\text { or } \\
(\mathrm{K}+\end{array}$ & $\begin{array}{c}\left.\mathrm{AgNO}_{3}\right) \\
\text { or } \\
\left.\mathrm{K}_{2} \mathrm{SO}_{4}\right) .\end{array}$ & 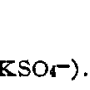 \\
\hline one & 53. & 3.19 & 40.3 & 30.26 & 10.04 & 0.0 & 0.0 & 0.0 \\
\hline 9.6 & I6. 96 & $x .82$ & $91 \cdot 75$ & 7.66 & 3.75 & 80.3 & 19.44 & 0.0 \\
\hline $9.96 \mathrm{~mm} . \mathrm{K}_{2} \mathrm{SO}_{4}$ & 48.04 & 2.0 & 30.5 & 74.0 & $13 \cdot 5$ & 75.0 & 5.0 & 18.0 \\
\hline
\end{tabular}

Table XIX.-Values of The Un-ionized Concentration and the Solubility Product in Solutions of Silver Sulfate.

(All concentrations in milliequivalents per liter.)

\begin{tabular}{|c|c|c|c|c|c|}
\hline \multirow[b]{2}{*}{ Added salt. } & Assum & intermed & on. & ssuming to & rmediate ion. \\
\hline & $\left(\mathrm{Ag}_{2} \mathrm{SO}_{4}\right) \cdot(\mathrm{Ag}$ & $\left.\mathrm{AgSO}_{4}-\right)$ & $+)^{2}\left(\mathrm{SO}_{4}=\right)$ & $\left(\mathrm{Ag}_{2} \mathrm{SO}_{4}\right)$ & $+)^{2}\left(\mathrm{SO}_{4}=\right)$ \\
\hline (a) None. & ‥ 3.19 & 405.0 & 49100.0 & 17.02 & 48640.0 \\
\hline (b) $99.60 \mathrm{~mm} . \mathrm{AgN}$ & I. 90 & 366.0 & 64500.0 & $7 \cdot 27$ & 78500.0 \\
\hline Ratios $b / a \ldots \ldots$ & 0.57 & 0.90 & I. 30 & 0.43 & I.6I \\
\hline (c) $99.96 \mathrm{~mm} \cdot \mathrm{K}_{2} \mathrm{SO}$ & 2.0 & $4 \mathrm{I} .2$ & 68800.0 & 20.94 & 70160.00 \\
\hline Ratio $c / a$ & 0.63 & 1.02 & 1.40 & I. 23 & I. 44 \\
\hline
\end{tabular}

The assumptions under which the calculations for Tables XVII to XIX were made do not define accurately the values which should be used, since the ionization constants for different uni-univalent salts are only approximately the same, and since the velocity of the intermediate ion could vary somewhat, though not greatly, without exerting a perceptible influence upon the values of the transference numbers. It should be understood, therefore, that the above calculations represent only very rough approximations. It would probably have been possible to have made these approximations more accurate by adopting certain auxiliary 
assumptions. One of the most valuable would have been to assume that the solubility products increase at about the same rate as in the case of uni-univalent salts for the same range of total ion concentrations. However, the object of the calculations was not to make accurate approximations, but to see if, on the basis of the assumptions which were chosen (see above), the behavior of the un-ionized concentration and of the solubility product would become less abnormal, and more in accord with what has been found for uni-univalent salts. An examination of Tables XVIII and XIX shows that the assumption of the presence of the intermediate ion in salts of the unibivalent type causes the abnormal increase in the un-ionized concentration when a salt with a common bivalent ion is added, to disappear, and in its place there is found to be a decrease comparable with that found for uni-univalent salts. If a salt with a common univalent ion is added the decrease in the un-ionized concentration becomes smaller when the presence of the intermediate ion is assumed, and in all cases the solubility product becomes more constant, as will be seen by a comparison of the ratios given in Table XIX. The effect of the assumption of the presence of intermediate ions in solutions of unibivalent salts is, therefore, to bring the behavior of the un-ionized concentration and of the solubility product into general accord with their behavior in solutions of uni-univalent salts.

25. Effect on the Solubility of Unibivalent Salts of a Substance with a Common Bivalent Ion Whose Own Intermediate Ion is Present in Large Proportion.

In discussing in the last section the effect on the solubility of a salt $\mathrm{A}_{2} \mathrm{~B}$ of another salt $\mathrm{D}_{2} \mathrm{~B}$, its own intermediate ion $\mathrm{DB}$ was shown to exert an effect in the same direction as the intermediate ion $A B$; namely, that of causing the decrease of solubility to be smaller than it would be if no intermediate ion were present. It was also shown that either ion, when present in sufficient proportion, may cause the decrease of solubility to pass over into an increase. It may now be pointed out that this last effect might be produced by the intermediate ion DB in a way different from that described, if in any special case it is present in unusually large proportion. Thus referring to equation (7) above, it will be seen that $S_{0}-S$ may change sign not only through a change in sign of the quantity within the bracket, but also through a change of sign of $(B)_{2}{ }^{1 / 2}-(B)_{0}{ }^{1 / 2}$. That is to say, there will be an increase of solubility in any case in which the salt $D_{2} B$ has so large a value of the ratio $(D B)_{2} /(B)_{2}$ that the effect of adding it to the solution of the salt $A_{2} B$ is to cause the $B$ ion of the latter to unite with the $D$ ion of the former to such an extent that the concentration of the B ion is decreased, rather than increased, by the added salt. That this may happen is clearly seen by considering the limiting case in which the salt $\mathrm{D}_{2} \mathrm{~B}$ dissociates only into the ions $\mathrm{D}$ and $\mathrm{DB}$, in which 
EFFECT OF SALTS UPON THE SOLUBILITY OF OTHER SALTS. VII. I 867

case the effect of adding it to a solution of the salt $A_{2} B$ dissociated into the ions $A$ and $B$ would obviously be simply to convert the ion $B$ into $\mathrm{DB}$ and thus increase the solubility.

This effect is well illustrated by the relative influences exerted on the solubility of silver sulfate by potassium sulfate, potassium hydrogen sulfate, and sulfuric acid. The fractional solubility ${ }^{1}$ in the presence

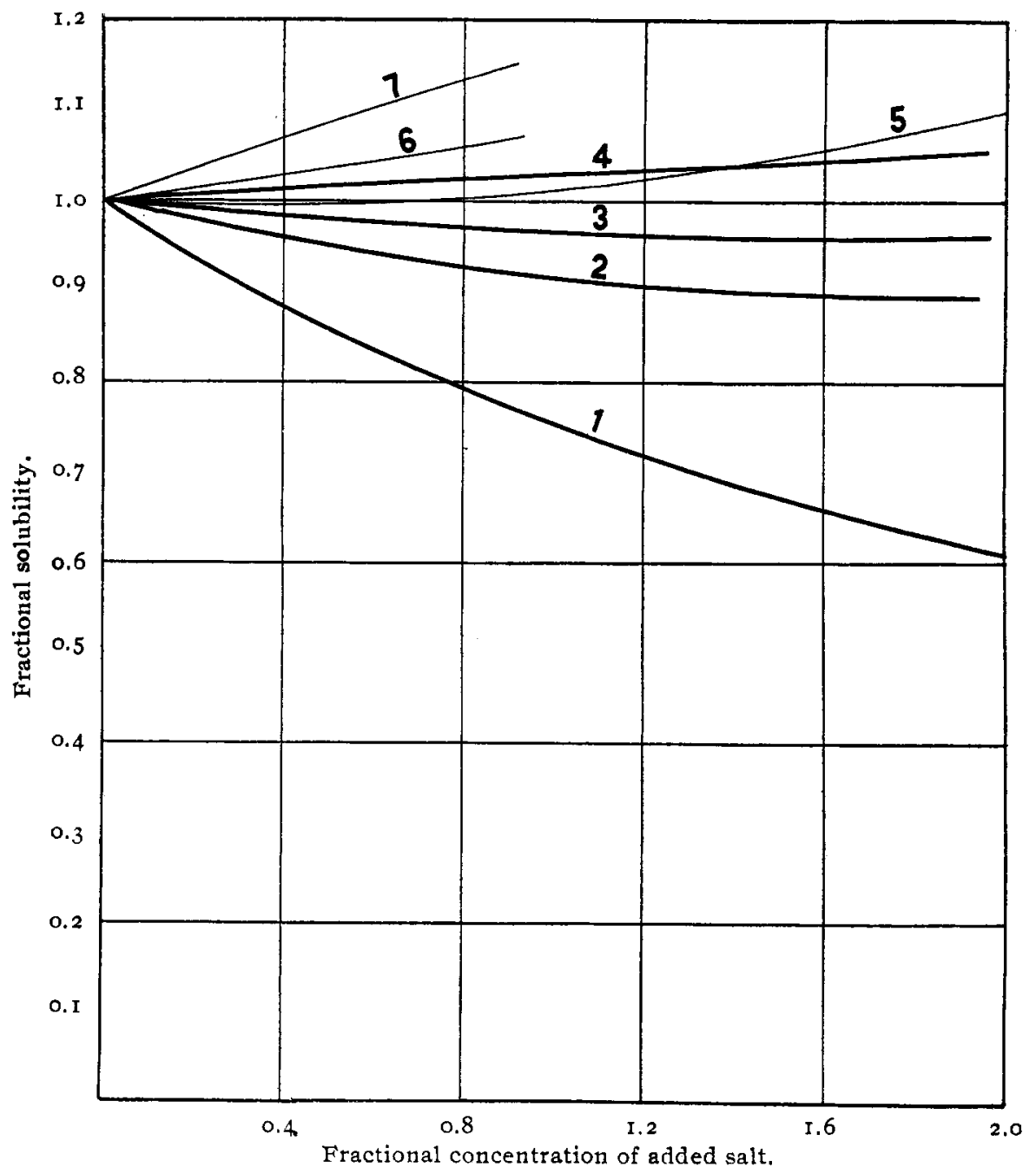

x. Theoretical limiting curve.

2. $\mathrm{Ag}_{2} \mathrm{SO}_{4}+\mathrm{K}_{2} \mathrm{SO}_{4}$.

3. $\mathrm{Ag}_{2} \mathrm{SO}_{4}+\mathrm{KHSO}_{4}$.

5. $-\mathrm{Tl}_{2} \mathrm{SO}_{4}+\mathrm{Na}_{2} \mathrm{SO}_{4}$.

6. $\mathrm{Tl}_{2} \mathrm{SO}_{4}+\mathrm{NaHSO}_{4}$.

4. $\mathrm{Ag}_{2} \mathrm{SO}_{4}+\mathrm{H}_{2} \mathrm{SO}_{4}$.

7. $\mathrm{Tl}_{2} \mathrm{SO}_{4}+\mathrm{H}_{2} \mathrm{SO}_{4}$.

Fig. 5.

'For the data see Paper V, Table II B. 
of these substances at different "fractional concentrations" is represented by the curves in Fig. 5, in which also the theoretical limiting curve corresponding to the assumption of complete ionization is plotted. It will be seen that the effect of potassium sulfate at all the concentrations (up to o. I normal) is to decrease the solubility, though very much less than the solubility-product principle would require; that that of potassium hydrogen sulfate is to cause a still smaller decrease; and that sulfuric acid produces an increase in the solubility. This marked difference in the effects of potassium sulfate and sulfuric acid is doubtless due to the different proportion of intermediate ion present in the solutions of these two substances. Thus, according to the estimate recorded in Table XVII, in o. I normal solution at $25^{\circ}$ potassium sulfate consists of 35 per cent. of $\mathrm{KSO}_{4}^{-}$and of 60 per cent. $\mathrm{SO}_{4}{ }^{2}$, and according to the estimate of Noyes and Stewart ${ }^{1}$ sulfuric acid consists of about 67 per cent. of $\mathrm{HSO}_{4}^{-}$and 27 per cent. $\mathrm{SO}_{4}^{-}$.

The estimate of the latter investigators, ${ }^{2}$ that in $O . I$ formal solution the acid sulfate yields 34 per cent. $\mathrm{SO}_{4}=$, shows, moreover, that the addition of anequivalent quantity of sulfuric acid to the solution of the neutral sulfate causes under these conditions only a small increase in the $\mathrm{SO}_{4}=$ concentration, namely, an increase from 0.060 to 0.068 normal. From these data (and the fact that the quantity of un-ionized $\mathrm{MHSO}_{4}$ present in this solution is 8 per cent. of the total $\mathrm{MHSO}_{4}$ ) one may calculate by equation ( 7$)$ that a neutral sulfate $\left(\mathrm{M}_{2} \mathrm{SO}_{4}\right)$, whose solubility in water was o. Ioo normal, would have a solubility 4.4 per cent. greater in a 0 . I normal solution of sulfuric acid.

Silver sulfate is a salt of only about half the solubility here considered, and its ionization is probably somewhat different from that of potassium or sodium sulfate; but the fact that its solubility is found to be about 5 per cent. greater in 0 . I normal sulfuric acid than in water shows that the general magnitude of the solubility effect is in accordance with that predicted from a consideration of the influence of the intermediate ion.

The effects of sodium sulfate, sodium hydrogen sulfate, and sulfuric acid on the solubility of thallous sulfate, for which the curves are also plotted in Fig. 5, bear the same relation to one another. All the curves have, of course, a higher position, owing to the greater solubility of the salt.

\section{Summary of Papers V, VI and VII on Unibivalent Salts.}

Paper V.-I. An accurate method for the analysis of bromates was described which consists in reducing the bromate to bromide by adding hydrazine hydroxide, acidifying with nitric acid, and precipitating as silver bromide.

1 ThIS JOURNAL, 32, II33 (I9IO).

${ }^{2}$ Loc. cit., p. 1159 . 
2. The solubility of silver sulfate was determined at $25^{\circ}$ in water and in solutions of magnesium nitrate, potassium nitrate, magnesium sulfate, potassium sulfate, and silver nitrate (see Tables I, II, and VII). The value for the solubility in water, 0.2676 mole per liter, is 4 . I per cent. higher than that obtained by Drucker (0.0257), and 0.86 per cent. lower than that obtained by Swan.

3. The solubility of barium bromate was determined at $25^{\circ}$ in water and in solutions of magnesium nitrate, potassiun nitrate, barium nitrate, and potassium bromate (see Tables III, IV, and VII). The solubility in water was found to be 0.04018 equivalent per liter. This value is 0.63 per cent. higher than that fotnd by Trautz and Anschütz.

4. The solubility of lead chloride at $25^{\circ}$ was determined in water and in solutions of lead nitrate. The solubility in water was found to be 0.07776 equivalent per liter, which is 0.08 per cent. higher than the value found by Noyes.

5. The conductance of all the solutions was measured at $25^{\circ}$. The values for the conductance and ionization of the salts are given in Tables VIII to XI.

6. The solubilities of the salts were plotted as ordinates, and the equivalent concentrations of the added salts as abscissas, and the solubility curves were found to belong to three types, as follows:

a. When a salt containing a common univalent ion is added, the solubility decreases rapidly, and the curve is qualitatively of the form to be expected from the solubility-product principle.

$b$. When a salt containing a common bivalent ion is added the change in solubility is altogether different from what would be expected from the solubility-product principle. The solubility of moderately soluble salts at first decreases slightly and then increases as the concentration of the added salt increases. With less soluble salts, such as barium bromate, the decrease is continuous, though slight, up to a concentration of 0.2 normal for the added salt. With extremely soluble salts the solubility increases from the beginning with increase in the concentration of the bivalent ion, and the curve is therefore of the form (c) which is found when a salt with no common ion is added.

c. When a salt with no common ion is added the solubility always increases. The rate of increase depends upon the degrees of ionization of the salts concerned in the metathesis which results from the mixing of the salts.

7. The addition of potassium hydrogen sulfate decreases the solubility of silver sulfate less than the addition of potassium sulfate, and the decrease caused by the latter is slight. Sulfuric acid increases the solubility. The curve in the latter case is intermediate between the curves for a common ion and those for no common ion. 
8. The addition of magnesium sulfate decreases the solubility of silver sulfate less than the addition of potassium sulfate.

9. The solubility relations of bivalent salts are expressed by two types of curves, that for the addition of a common ion and that for the additon of a salt with no common ion.

Io. While the solubility curves for the addition of a salt with a common bivalent ion to a very soluble unibivalent salt are of a form altogether different from what would be expected from the solubility-product principle, it is shown that the curves for the less soluble salts are approaching the theoretical form.

Paper VI.-II. The solubility of barium iodate in water at $25^{\circ}$ was found to be 0.001579 , and of lead iodate 0.0001 ro2 equivalent per liter.

12. The solubility of barium iodate was determined in solutions of potassium nitrate, barium nitrate, and potassium iodate.

I3. The solubility of lead iodate was determined in solutions of potassium nitrate, lead nitrate, and potassium iodate.

I4. When a salt with a common bivalent ion is added to solutions of these slightly soluble salts, the solubility curves are very nearly of the theoretical form in the more dilute solutions.

I5. When a salt with a common univalent ion is added, the solubility of these salts decreases with extreme rapidity, and when a salt with no common ion is added, the solubility increases rapidly.

I6. The solubility curves for the addition of a common ion are shown to assume practically the same form as those for the addition of a salt with no common ion in the case of very soluble salts, like strontium nitrate.

Paper VII.-I 7. The concentrations of the un-ionized part and of the ions of the salt saturating the solution were calculated for all of the mixtures from the ionization of the salts in pure water under the assumption that the only ions present are the simple ions. The results are given in Tables I to IV.

I8. The solubility product for these unibivalent salts increases farmore rapidly than that for uni-univalent salts (see Tables V to VIII, Figs. I to 3). It increases rapidly, whatever the type of the added salt; but the increase is somewhat more rapid when the common ion added is univalent than when it is bivalent. The rate of the increase may be expressed (for a salt $A_{2} B$ ) by equations of the form

$$
(\mathrm{A})^{2}(\mathrm{~B})=k\left(\Sigma_{i}\right)^{m_{i}} \text {, or } \log (\mathrm{A})^{2}(\mathrm{~B})=m_{i} \log \left(\Sigma_{i}\right)+\log k_{i} \text {. }
$$

In these equations $m_{i}$ has, for ion concentrations between 0.03 and 0 . Io normal, an average value of about 0.45 when the common ion added is univalent, and one of about 0.34 when it is bivalent. The solubility product remains more nearly constant the smaller the solubility of the salt. 
19. The decrease in the concentration of the un-ionized part of a univalent salt, caused by adding another salt to its saturated solution, is shown to be very much more rapid than the decrease in the solubility of a non-electrolyte caused in the same way. When the salt saturating the solution is unibivalent the decrease in the concentration of the unionized part is greater when a salt with a common univalent ion is added than the similar decrease observed for uni-univalent salts. When a salt with no common ion is added the decrease in the concentration of the un-ionized part is much less rapid, and when a salt with a common bivalent ion is added, there is an increase instead of a decrease. The increase in the concentration of the un-ionized part when a common bivalent ion is added becomes smaller as the solution becomes more dilute, while the decrease in the un-ionized part caused by the common univalent ion becomes larger as the concentration of the solution decreases.

20. The results are expressed by equations of the form

$$
\left(\mathrm{A}_{2} \mathrm{~B}\right)=k_{u}\left(\Sigma_{i}\right)^{m_{u}} ; \text { or } \log \left(\mathrm{A}_{2} \mathrm{~B}\right)=m_{u} \log \left(\Sigma_{i}\right)+\log k_{u} \text {. }
$$

The values of $m_{u}$ are shown to be very irregular and to depend in an extraordinary degree on the type of ion added to the solution.

$2 \mathrm{I}$. The solubility effects produced by adding a common ion have also been discussed in another way, namely, by expressing the concentrations both of the salt saturating the solution and of the added salt in terms of the solubility of the former salt in pure water. Curves have been presented in Fig. 4 which show the change of this "fractional solubility" with the "fractional concentration" of the added salt in relation to the solubility of the salt saturating the solution and the type of the added salt, and in relation to the "theoretical limiting curve" representing the solubility decrease under the assumption that both salts are completely ionized. The actual curves lie in general not far above the limiting curve when the common univalent ion is added, whatever be the solubility. The curves for the addition of the common bivalent ion lie near the limiting curve for very slightly soluble salts, like lead iodate; but they deviate more and more from it as the solubility increases, finally approaching the position of the curves for the addition of a salt with no common ion.

22. Lead chloride in its solubility relations behaves like a salt of greater solubility. This is probably related to its abnormal ionization, which is indicated by the unusually small value of its conductance ratio.

23. The irregular variation of the un-ionized part, the abnormal increase in the solubility product, and the abnormal form of the solubility curve for the addition of the common bivalent ion are remarkable results which require some general explanation.

24. The simplest hypothesis which brings these results into harmony with each other and with the behavior of uni-univalent salts is that all 
unibivalent salts dissociate in two steps, and therefore give rise to an intermediate ion of the type $\mathrm{KSO}_{4}^{-}$or $\mathrm{BaNO}_{3}{ }^{+}$. As a general explanation of the solubility phenomena, this is believed to be a new suggestion. Previous assumptions of the existence of the intermediate ion had been made only in specific cases and to explain abnormal results which were believed to be quite specific in their nature. It is here assumed that the proportion of the intermediate ion increases with the concentration, and that it has in general roughly the same value for salts of the same valence type at any given concentration.

25. It is shown that this hypothesis leads to a number of definit deductions as to the direction and general magnitude of the changes in the solubility of unibivalent salts produced by the addition of other salts with both a common univalent and a common bivalent ion; and it is shown that these conclusions are in complete accord with the experimental values. The demonstrated correspondence of these deductions with the facts is thought to constitute the most important theoretical result of these investigations. The deductions are not reproduced here as they have already been stated in summarized form in the paragraphs numbered (I) to (6) in Section 24.

26. Two principles are suggested, by a combination of which the proportion of the intermediate ion present in solutions of unibivalent salts may be approximately determined; and the results of calculations are presented (in Tables XVII and XVIII), showing the concentration of the different constituents in certain solutions of silver sulfate and of potassium sulfate, and in saturated solutions of silver sulfate containing also silver nitrate and potassium sulfate. It is shown (in Table XIX) that the solubility product $\left(\mathrm{Ag}^{+}\right)^{2}\left(\mathrm{SO}_{4}{ }^{3}\right)$ remains much more nearly constant, and that there is a normal decrease instead of the abnormal increase in the concentration of the un-ionized part for the case where a salt with a common bivalent ion is added, when the presence of the intermediate ion is taken into account.

27. It is shown that the facts that potassium sulfate decreases and that sulfuric acid increases the solubility of silver sulfate are explained by the consideration that the proportion of the intermediate ion $\mathrm{HSO}_{4}^{-}$ present in the acid solution is much larger than the proportion of the intermediate ion $\mathrm{KSO}_{4}^{-}$present in the potassium sulfate solution. A quantitative estimate of the effect that should be exerted by sulfuric acid on the solubility of a neutral sulfate of moderate solubility is shown to be in agreement with that observed in the case of silver sulfate.

In conclusion, I wish to thank Professor A. A. Noyes for many helpful suggestions in regard to this work on unibivalent salts; and especially for his revision of the theoretical part of the seventh paper. I wish also to thank Professor W. C. Bray for suggestions in connection with the cal- 
culations. Grateful acknowledgments are also due to the Carnegie Institution of Washington, whose financial assistance has made this work possible.

Boston, Mass.

[CONTributions from THE Hatemeyer Chemical, Laboratory, NeW York UNTVERSITY.]

\section{AN EQUILIBRIUM IN THE COBALTAMMINES. ${ }^{1}$}

By ARTHUR B. LAMB AND JOHN W. MARDEN.

Received July 20, IgII.

The ammonia compounds of cobalt salts, called the cobaltammines to distinguish them from the organic amines, constitute an unusually interesting group of substances. A great number of them have been prepared; they have been arranged in numerous well defined classes, and the systematic correlation of these classes has been well worked out. They exhibit points of marked similarity with organic substances; thus they contain complex radicals entirely analogous in their behavior to organic radicals; they exhibit structural and stereomeric isomerism quite as striking as that of many organic substances; substitutions can be made with an even greater freedom than in organic compounds. On the other hand, these compounds are distinctly inorganic; they are for the most part salts, more or less soluble in water, and more or less electrolytically dissociated.

These unusual substances offer particular advantages for the study of such fundamental chemical problems as valency, the connection between chemical nature and electrolytic dissociation, etc. Indeed, they have already given rise to one theory of valency (Werner's), which, even if it may ultimately prove incorrect, has nevertheless furnished a simple and comprehensive correlation of this group and of other similar groups. However, for a study of any of these problems a knowledge of the energetic relationships is important. We ought, for instance, to know the difference in the total and free energy of formation of the different isomers and part isomers in this group; or, if possible, the difference in free or total energy between a partial and principal valency in the sense of Werner's theory. There is at present no information whatever on these subjects, and it was in the hope of making good some of this deficiency that this research was undertaken.

The most promising point of attack appeared to be the spontaneous transformations which many of the cobaltammines undergo either in the dry state or in solution. If these transformations could be shown to approach equilibria, the free energy change, or the affinity of the reactions,

${ }^{1}$ Presented at the June, IgII, meeting of the New York Section of the American Chemical Society. 